Sharif University of Technology
Scientia Iranica
Transactions E: Industrial Engineering
wCIEw.scientiairanica.com

\title{
Two-warehouse inventory model for deteriorating items with imperfect quality under the conditions of permissible delay in payments
}

\author{
C.K. Jaggi ${ }^{a}$, L.E. Cárdenas-Barrón ${ }^{b, *}$, S. Tiwari ${ }^{a}$ and A.A. Shafi ${ }^{a}$ \\ a. Department of Operational Research, Faculty of Mathematical Sciences, New Academic Block University of Delhi, Delhi-110007, \\ India. \\ b. School of Engineering and Sciences, Tecnológico de Monterrey, E. Garza Sada 2501 Sur, C.P. 64849, Monterrey, Nuevo León, \\ México.
}

Received 5 August 2015; received in revised form 19 September 2015; accepted 14 December 2015

\section{KEYWORDS \\ Inventory; \\ Deterioration; \\ Imperfect items; \\ Two-warehouse; \\ Inspection; \\ Trade credit.}

\begin{abstract}
Regularly, manufacturing systems produce perfect and imperfect quality items. The perfect items start deteriorating as soon as they enter inventory. On the other hand, the suppliers make a delay in payment in order to motivate their buyers to purchase more products. This paper develops a two-warehouse inventory model that jointly considers the imperfect quality items, deterioration, and one level of trade credit. The proposed inventory model optimizes the order quantity to maximize the total profit per unit time. Finally, the proposed inventory model and its solution procedure are validated with numerical examples and a sensitivity analysis is done to show how inventory model reacts to changes in parameters.

(C) 2017 Sharif University of Technology. All rights reserved.
\end{abstract}

\section{Introduction}

Nowadays, production managers apply and implement efficacious manufacturing planning and complex production and control systems in order to have $100 \%$ quality items. However, the manufacturing process may still produce defective items. The defective items reduce the profit for the retailer and their inadvertent supply to customer may cost the retailer to lose goodwill. Thus, to sustain the supply of good quality items, it is vital for the whole lot to be screened as soon as it comes into the inventory and the defective items identified must be removed from the lot. With this in mind, a great amount of research has been made in the direction of the development EOQ/EPQ models

*. Corresponding author. Tel.: +52 8183284235 ;

Fax: +528183284153

E-mail address: lecarden@itesm.mx(L.E.

Cárdenas-Barrón) for defective items. Porteus [1] found a significant relationship between the fraction of defective items and the lot. Rosenblatt and Lee [2] and Lee and Rosenblatt [3] showed through their papers that the presence of defective items forces the lot size to be smaller. Salameh and Jaber [4] expanded the research made for imperfect quality items considering random yield. They developed an EOQ model that refuted the results of Rosenblatt and Lee [2]. Salameh and Jaber [4] concluded that the batch quantity increased as the average percentage of imperfect quality items rose. Cárdenas-Barrón [5] corrected an error in the model of Salameh and Jaber [4] without affecting its main idea. Goyal and Cárdenas-Barrón [6] proposed an easy to apply method to determine the lot size in the model of Salameh and Jaber [4]. Papachristos and Konstantaras [7] examined the issue of non-shortages in the model of Salameh and Jaber [4] with proportional imperfect quality when the proportion of the imperfect was a random variable. Moussawi-Haidar et al. [8] 
studied the effect of deterioration on the instantaneous replenishment of the lot with imperfect quality items.

The items in inventory are under numerous risks like breakage, obsolescence, and evaporation. Another phenomenon that significantly affects items in inventory, e.g. gasoline, chemicals, and food items, which deteriorate fast through time, is deterioration. Thus, the loss by deterioration cannot be disregarded. Researchers have been progressively modifying the existing inventory models for deteriorating items in order to make them more realistic. Goyal and Giri [9] presented a complete review of research on deteriorating items published up to 2001. Bakker et al. [10] provided an extensive and comprehensive review on advancements in the field of inventory control of deteriorating items.

In order to avoid the losses related to deterioration, a retailer may rent another warehouse with better preserving facilities than those of his/her own warehouse. Moreover, the trade credit period provided by supplier motivates the retailer to purchase a quantity that exceeds the owned warehouse capacity and, consequently, the retailer needs to rent another warehouse for storage. The two-warehouse inventory system was first proposed by Hartley [11]. Das et al. [12] studied joint performance of a supply chain with two warehouse facilities. Hsieh et al. [13] proposed a deterministic inventory model for deteriorating items with two warehouses that minimized the net present value of the total cost. Several research papers in this interesting area were published by researchers in the last few decades [14-18].

The EOQ assumes that when the retailers receive the order, they immediately pay their suppliers. However, this is not always true. To facilitate the business for retailers, the suppliers sometimes make a delay in payment to retailers for a fixed time period to settle the payment of the order without charging any interest on the retailers during this credit period. But, an interest is charged at pre-determined rate if payment is not made by the end of the established credit period. Both the retailer and the supplier benefit from credit period. During the period before the account has to be paid, the buyers can vend products and accumulate revenue, and earn interest by placing revenue within an interest bearing account. The delay in payment period motivates the retailers to order more products and, thus, turns out to be beneficial for the supplier. It is important to remark that large orders increase holding cost and losses due to deterioration. Naturally, the retailer must consider all pros and cons while ordering into bulk in order to earn a maximum profit.

This paper proposes a two-warehouse inventory model that considers imperfect quality items under deteriorating conditions and permissible delay in payments. The lot is screened as soon as it enters the inventory system. The screening rate is assumed to be greater than the demand rate so that the demand can be satisfied along with the screening running in parallel, out of the items which are perfect in quality. Shortages are not allowed. The inventory model optimizes retailer's order quantity by maximizing his/her total profit.

\section{Assumptions and notation}

The mathematical model for the two-warehouse inventory problem is based on the following assumptions:

1. The Owned Warehouse (OW) has a fixed capacity of $w$ units; the Rented Warehouse (RW) has unlimited capacity;

2. The initial inventory level and lead time are zero;

3. The deterioration rate of $\operatorname{RW}(\beta)$ is less than the deterioration rate of $\mathrm{OW}(\alpha)$;

4. The screening process and demand occur simultaneously, but the screening rate $(x)$ is greater than the demand rate $(D), x>D$;

5. The supplier provides a fixed credit period to the retailer to settle the account;

6. Shortages are not allowed;

7. The defective items exist in lot size $y$. The percentage of defective items is a random variable $(p)$ with:

$$
E(p)=\int_{l_{1}}^{l_{2}} p f(p) d p ; \quad 0<l_{1}<l_{2}<1 .
$$

The following notations are used:

$y$

variable

$w \quad$ Storage capacity of OW (units)

$D \quad$ Demand rate per unit time (unit/time unit)

$p \quad$ Percentage of defective items in $y(\%)$

$f(p) \quad$ Probability function of $p$

$t_{s} \quad$ Screening time of RW (time unit)

$t_{w} \quad$ Screening time of OW (time unit)

$t_{r} \quad$ Time point when the stock level of RW reaches zero (time unit)

$T \quad$ The replenishment cycle (time unit)

$M \quad$ The retailer's trade credit period provided by the supplier (time unit)

$I_{o}(t) \quad$ Inventory level of OW at time $t$ (units)

$I_{r}(t) \quad$ Inventory level of RW at time $t$ (units)

$X \quad$ Screening rate (unit/time unit)

$\alpha \quad$ Deterioration rate of OW

$\beta \quad$ Deterioration rate of RW

$c \quad$ Unit purchasing cost per item (\$/unit) 
$k \quad$ Fixed cost of placing an order ( $\$$ /order)

$s \quad$ Unit selling price per item of good items (\$/unit)

$v \quad$ Unit selling price per item of defective items $(\$ /$ unit)

d Unit screening cost per item (\$/unit)

$I_{e} \quad$ Interest earned (\%/unit time)

$I_{p} \quad$ Interest paid (\%/unit time)

$h_{r} \quad$ Holding cost per unit item per unit time in RW, excluding interest charges (\$/unit/time unit)

$h_{o} \quad$ Holding cost per unit item per unit time in $\mathrm{OW}$, excluding interest charges (\$/unit/time unit)

$\mathrm{HC}_{r} \quad$ Inventory holding cost of RW (\$/time unit)

$\mathrm{HC}_{o} \quad$ Inventory holding cost of OW (\$/time unit)

TPU $(y) \quad$ The total profit per unit time $(\$ /$ time unit)

\section{Model formulation}

We consider that a lot of size $y$ enters the inventory system, out of which $w$ units are placed in OW and $(y-w)$ units are stored in RW. The RW is considered to have better preserving facilities than OW and, hence, deterioration rate of RW $(\beta)$ is less than the deterioration rate of OW $(\alpha)$. The holding cost at RW is greater than the holding cost at OW $\left(h_{r}>h_{o}\right)$. In any production process, due to certain reasons such as improper transport, low labor skills, low quality of raw materials, among others, the production process may shift to an imperfect production process in which not all the items manufactured are of good quality. Due to this, a screening process must be conducted at screening rate of $(x)$ units per unit time when the whole lot enters the inventory. It is assumed that each received lot $y$ contains $p$ percent of defective items, where $p$ is a random variable with a known probability density function, $f(p)$, and mean, $E(p)=p$. Thus, lot $y$ has $p y$ defective items and $(1-p) y$ non-defective items. The defective items found are kept in stock and sold at the end of the screening period at a salvage value of $(v)$ per unit, $v<$ $c$. The screening process takes place in OW and RW, simultaneously, and gets completed at $t_{w}=w / x$ and $t_{s}=(y-w) / x$, respectively. Depending on the values of $t_{w}, t_{s}$, and $t_{r}$, the following cases are discussed.

\section{Case I: When $t_{w}<t_{r}$}

This case considers that the screening period of OW $\left(t_{w}\right)$ is less than the time point $\left(t_{r}\right)$ when the stock level of RW reaches zero. The inventory in RW depletes due to demand and deterioration from $\left[0, t_{r}\right]$ and reaches zero. The inventory in OW depletes only due to deterioration during $\left[0, t_{r}\right]$ and, then, by both demand and deterioration during $\left[t_{r}, T\right]$. The behavior of the inventory model through the whole cycle $[0, T]$ is shown graphically in Figures 1 and 2 .

The differential equations that model the inventory level in both warehouses RW and OW at any time, $t$, over the period $(0, T)$ are:

$$
\begin{array}{ll}
\frac{d I_{r}(t)}{d(t)}+\beta I_{r}(t)=-D & 0 \leq t \leq t_{r}, \\
\frac{d I_{o}(t)}{d t}=-\alpha I_{o}(t) & 0 \leq t \leq t_{r},
\end{array}
$$

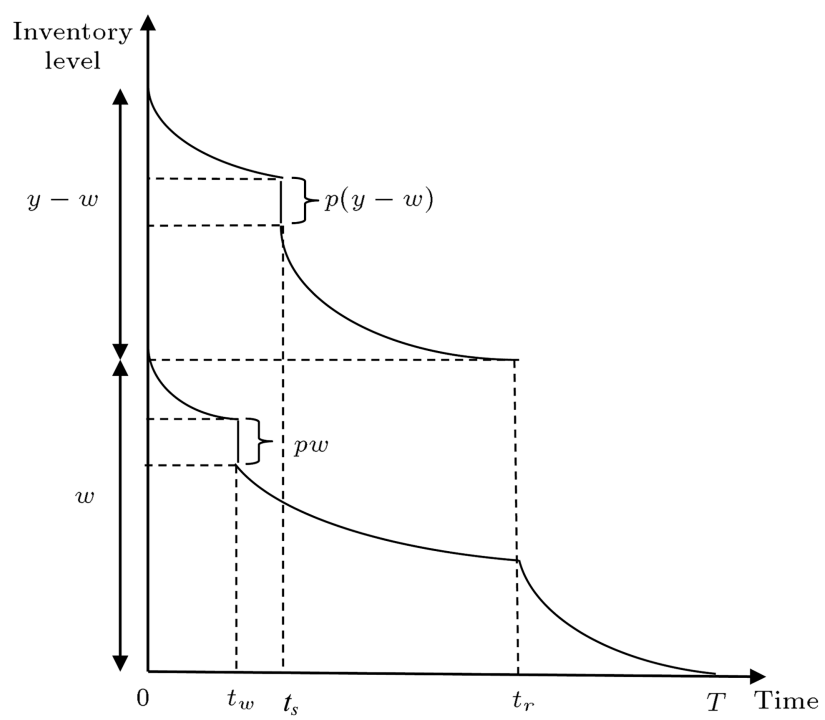

Figure 1. Inventory level for the two-warehouse system when $t_{w}<t_{s}<t_{r}$.

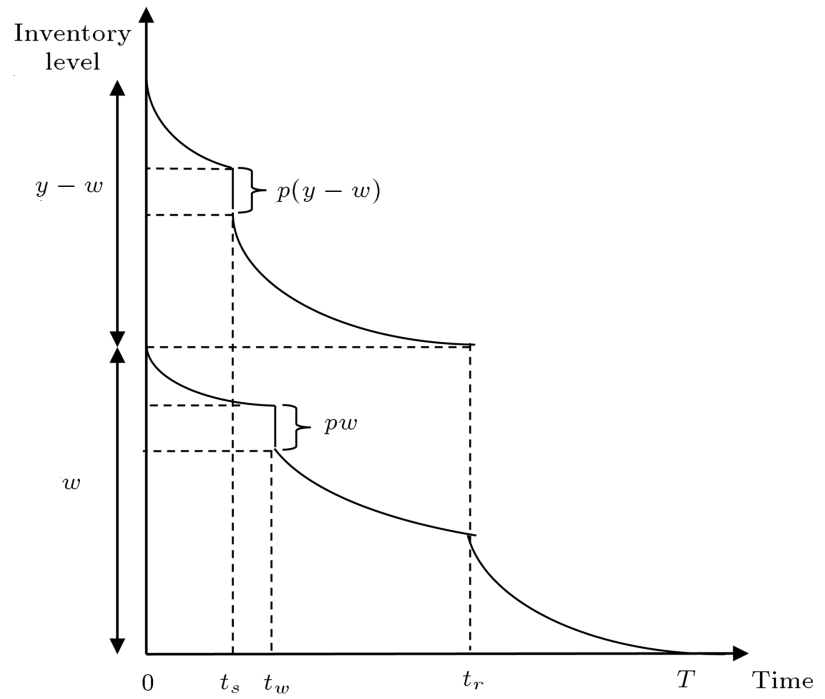

Figure 2. Inventory level for the two-warehouse system when $t_{s}<t_{w}<t_{r}$. 


$$
\frac{d I_{o}(t)}{d t}+\alpha I_{o}(t)=-D \quad t_{r} \leq t \leq T .
$$

Solving the above differential equations with the boundary conditions $I_{r}(0)=y-w, I_{r}\left(t_{s}^{+}\right)=I_{r}\left(t_{s}\right)-$ $p(y-w), I_{o}(0)=w, I_{o}\left(t_{w}^{+}\right)=I_{o}\left(t_{w}\right)-p w$, and $I_{o}(T)=0$, the solutions are:

$$
\begin{array}{rlrl}
I_{r}(t) & =-\frac{D}{\beta}+\left(y-w+\frac{D}{\beta}\right) e^{-\beta t} & 0 \leq t \leq t_{s}, \\
I_{r}(t) & =-\frac{D}{\beta}+\left((y-w)+D / \beta-p(y-w) e^{\beta t_{s}}\right) e^{-\beta t} \\
t_{s} & <t \leq t_{r}, & & \leq t \leq t_{w}, \\
I_{o}(t) & =w e^{-\alpha t} & t_{w}<t \leq t_{r}, \\
I_{o}(t) & =\left\{w-p w e^{\alpha t_{w}}\right\} e^{-\alpha t} & t_{r} \leq t \leq T . \\
I_{o}(t) & =\frac{D}{\alpha}\left(e^{\alpha(T-t)}-1\right) &
\end{array}
$$

Applying the boundary condition $I_{r}\left(t_{r}\right)=0$, the value of $t_{r}$ is:

$$
t_{r}=\frac{1}{\beta}\left\{\ln \left(1+\frac{\beta}{D}(y-w)\left(1-p e^{\beta t_{s}}\right)\right)\right\} .
$$

Considering the continuity of $I_{o}(t)$ at $t=t_{r}$, the value for $T$ is:

$$
\begin{aligned}
& \left(w-w p e^{\alpha t_{w}}\right) e^{-\alpha t_{r}}=\frac{D}{\alpha}\left\{e^{\alpha\left(T-t_{r}\right)}-1\right\}, \\
& T=t_{r}+\frac{1}{\alpha} \ln \left[\frac{\alpha}{D}\left(w-p w e^{\alpha t_{w}}\right) e^{-\alpha t_{r}}+1\right] .
\end{aligned}
$$

\section{Case II: When $t_{w}>t_{r}$}

Figure 3 shows the behavior of the inventory model over the time interval $[0, T]$. It is assumed that the screening period of OW $\left(t_{w}\right)$ is greater than the time point $\left(t_{r}\right)$ when the stock level of RW reaches zero. The inventory in RW diminishes due to demand and deterioration from $\left[0, t_{r}\right]$ and reaches zero. The inventory in $\mathrm{OW}$ diminishes only due to deterioration during $\left[0, t_{r}\right]$ and, then, by both demand and deterioration during $\left[t_{r}, T\right]$.

Notice that the equations for the inventory level of RW are identical to those in Case I. Thus, the differential equations and their solutions for OW are:

$$
\begin{array}{ll}
\frac{d I_{o}(t)}{d t}=-\alpha I_{o}(t) & 0 \leq t \leq t_{r}, \\
\frac{d I_{o}(t)}{d t}+\alpha I_{o}(t)=-D & t_{r} \leq t \leq T .
\end{array}
$$

Solving the above differential equations with the boundary conditions, $I_{o}(0)=w, I_{o}\left(t_{w^{+}}\right)=I_{o}\left(t_{w}\right)-p_{w}$,

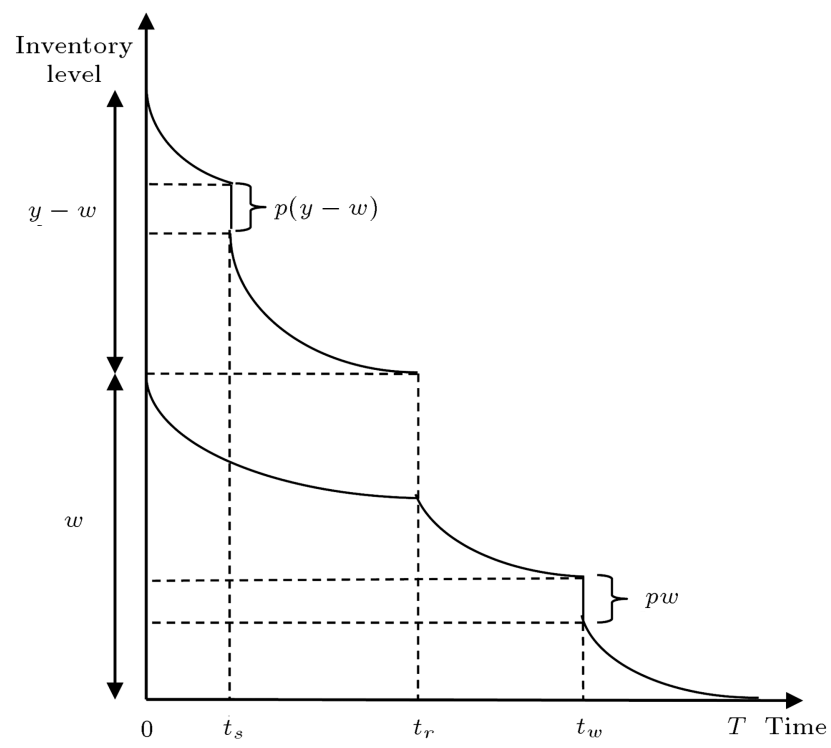

Figure 3. Inventory level for the two-warehouse system when $t_{s}<t_{r}<t_{w}$.

and continuity of $I_{o}(t)$ at $t=t_{r}$, the solutions are:

$$
\begin{aligned}
I_{o}(t) & =w e^{-\alpha t} \quad 0 \leq t \leq t_{r} \\
I_{o}(t) & =\frac{-D}{\alpha}+\left(w e^{-\alpha t_{r}}+\frac{D}{\alpha}\right) e^{-\alpha\left(t-t_{r}\right)} \\
t_{r} & \leq t \leq t_{w} \\
I_{o}(t) & =\frac{-D}{\alpha}+\left(w e^{-\alpha t_{r}}+\frac{D}{\alpha}-p w e^{\alpha\left(t_{w}-t_{r}\right)}\right) e^{-\alpha\left(t-t_{r}\right)} \\
t_{w} & <t \leq T
\end{aligned}
$$

$I_{o}(T)=0$ implies:

$$
T=t_{r}+\frac{1}{\alpha} \ln \left[\frac{\alpha}{D}\left(w-p w e^{\alpha t_{w}}\right) e^{-\alpha t_{r}}+1\right] .
$$

It is easy to see that the total time cycle $T$ is identical to that in Case I.

Now, let $N_{r}(y, p)$ and $N_{o}(y, p)$ be the totals of good items in each lot at time $t$ with respect to RW and $\mathrm{OW}$, respectively. These items are obtained by removing the defective and deteriorated items from the inventory. Let $w_{1 r}$ and $w_{1 o}$ be the total numbers of deteriorated items during time intervals $\left[0, t_{r}\right]$ and $[0, T]$ in RW and OW, respectively:

$$
\begin{aligned}
& N_{r}(y, p)=(y-w)(1-p)-w_{1 r} \\
& N_{o}(y, p)=w(1-p)-w_{1 o} .
\end{aligned}
$$

Let $I_{01 r}(t)$ be the inventory level of RW at time $t$ when both effects of lot quality and deterioration are ignored; thus, $I_{01 r}(t)=-D t+y-w$. Let $I_{02 r}(t)$ be the inventory level of RW when only the effect of deterioration is 


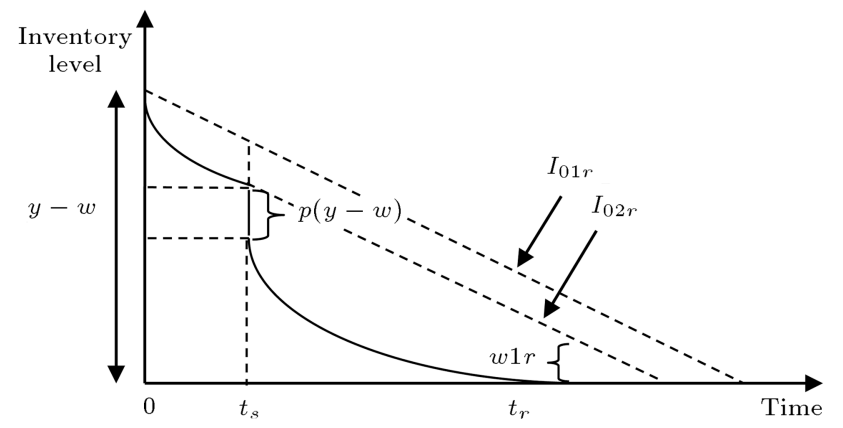

Figure 4. Inventory level for rented warehouse showing the deteriorated items at time $t_{r}$.

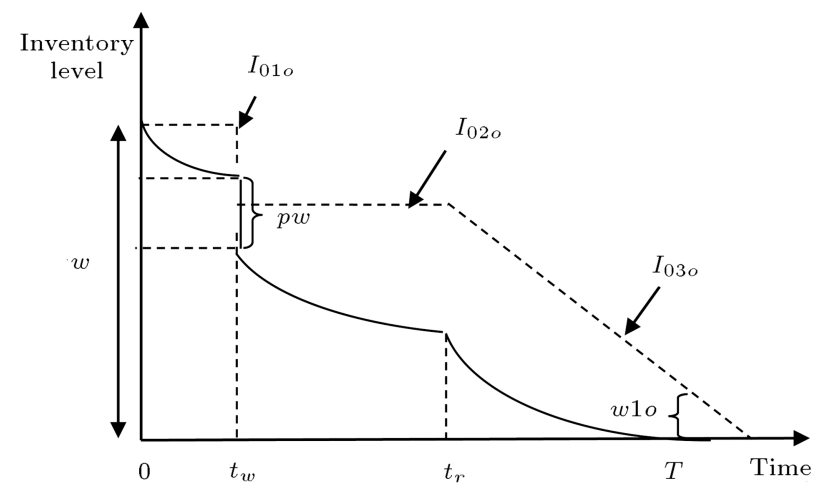

Figure 5. Inventory level for the owned warehouse showing the deteriorated items at time $T$.

ignored; hence, $I_{02 r}(t)=-D t+(y-w)(1-p)$. According to Figure $4, w_{1 r}$ is:

$$
w_{1 r}=I_{02 r}\left(t_{r}\right) \text {. }
$$

Let $I_{01 o}(t)$ be the inventory level of OW at time $t$ when both effects of lot quality and deterioration are ignored; thus, $I_{01 o}(t)=w$. Let $I_{02 o}(t)$ and $I_{03 o}(t)$ be the inventory levels of OW when only the effect of deterioration is ignored; hence, $I_{02 o}(t)=w-p w$ and $I_{03 o}(t)=$ $-D\left(t-t_{r}\right)+w-p w$. According to Figure $5, w_{1 o}$ is:

$$
w_{1 o}=I_{03 o}(T) \text {. }
$$

To avoid shortages, it is assumed that the totals of good items $N_{r}(y, p)$ and $N_{o}(y, p)$ are at least equal to the demands during screening times, i.e. $t_{s}$ and $t_{w}$ :

$$
\begin{aligned}
& N_{r}(y, p) \geq D t_{s}, \\
& N_{o}(y, p) \geq D t_{w} .
\end{aligned}
$$

From Eqs. (21) and (22), the percent of defective items $(p)$ must satisfy:

$$
\begin{gathered}
p \leq \min \left(\frac{-D}{\beta(y-w)}+\left(1+\frac{D}{\beta(y-w)}\right) e^{-\beta t_{s}},\right. \\
\left.\left(1-\frac{D}{w \alpha}\left(e^{\alpha t_{w}}-1\right) a^{\alpha t_{r}}\right) e^{-\alpha t_{w}}\right) .
\end{gathered}
$$

The retailer's total profit during a cycle $T P_{i . j}(y)$, (where $i=$ Case 1 - Case 3 and $j=$ Sub-case 1 to Sub-case 5) is comprised of the following terms:

$$
\begin{aligned}
T P_{i . j}(y)= & \text { Sales revenue }+ \text { Interest earned } \\
& - \text { Ordering cost }- \text { Purchasing cost } \\
& - \text { Screening cost }- \text { Holding cost } \\
& - \text { Interest paid } \text {. }
\end{aligned}
$$

Thus:

$$
\begin{aligned}
T P_{i . j}(y)= & \text { Sales revenue }+ \text { Interest earned }-k \\
& -c y-d y-\text { Holding cost }- \text { Interest paid. }
\end{aligned}
$$

Sales revenue, $T R$, is the sum of the total sale volumes of good quality and imperfect quality items from RW and OW:

$$
\begin{aligned}
T R= & s\left((y-w)(1-p)-w_{1 r}+w(1-p)-w_{1 o}\right) \\
& +v(y-w) p+v w p .
\end{aligned}
$$

By replacing $w_{1 r}$ and $w_{1 o}, T R$ becomes:

$$
T R=s D T+v y p .
$$

The inventory holding cost per cycle in RW is:

$$
\begin{aligned}
\mathrm{HC}_{r}= & h_{r}\left\{\int_{0}^{t_{s}} I_{r}(t) d(t)+\int_{t_{s}}^{t_{r}} I_{r}(t) d(t)\right\} \\
= & h_{r}\left\{\frac{y-w}{\beta}(1-p)\right. \\
& \left.-\frac{D}{\beta^{2}}\left\{\ln \left(\frac{\beta}{D}(y-w)\left(1-p e^{\beta t_{s}}\right)+1\right)\right\}\right\} .
\end{aligned}
$$

The inventory holding cost per cycle in OW for the case with $t_{w}<t_{r}$ is:

$$
\begin{aligned}
& \mathrm{HC}_{o}=h_{o}\left\{\int_{0}^{t_{w}} I_{o}(t) d t+\int_{t_{w}}^{t_{r}} I_{o}(t) d t+\int_{t_{r}}^{T} I_{o}(t) d t\right\} \\
&= h_{o}\left\{\frac{w}{\alpha}(1-p)-\frac{D}{\alpha^{2}} \ln \left\{\frac{\alpha}{D}\left(w-w p e^{\alpha t_{w}}\right) e^{-\alpha t_{r}}\right.\right. \\
&+1\}\} .
\end{aligned}
$$

The inventory holding cost per cycle in OW for the case with $t_{r}<t_{w}$ is: 
Table 1. Different sub-cases in each main case.

\begin{tabular}{cll}
\hline \multicolumn{1}{c}{ Case 1: } & \multicolumn{1}{c}{ Case 2: } & \multicolumn{1}{c}{ Case 3: } \\
$\boldsymbol{t}_{\boldsymbol{w}}<\boldsymbol{t}_{\boldsymbol{s}}<\boldsymbol{t}_{\boldsymbol{r}}$ & $\boldsymbol{t}_{\boldsymbol{s}}<\boldsymbol{t}_{\boldsymbol{w}}<\boldsymbol{t}_{\boldsymbol{r}}$ & \multicolumn{1}{c}{$\boldsymbol{t}_{\boldsymbol{s}}<\boldsymbol{t}_{\boldsymbol{r}}<\boldsymbol{t}_{\boldsymbol{w}}$} \\
\hline Sub-case 1.1: $0<M \leq t_{w}<t_{s}<t_{r}$ & Sub-case 2.1: $0<M \leq t_{s}<t_{w}<t_{r}$ & Sub-case 3.1: $0<M \leq t_{s}<t_{r}<t_{w}$ \\
Sub-case 1.2: $t_{w}<M \leq t_{s}<t_{r}$ & Sub-case 2.2: $t_{s}<M \leq t_{w}<t_{r}$ & Sub-case 3.2: $t_{s}<M \leq t_{r}<t_{w}$ \\
Sub-case 1.3: $t_{w}<t_{s}<M \leq t_{r}$ & Sub-case 2.3: $t_{s}<t_{w}<M \leq t_{r}$ & Sub-case 3.3: $t_{s}<t_{r}<M \leq t_{w}$ \\
Sub-case 1.4: $t_{w}<t_{s}<t_{r}<M \leq T$ & Sub-case 2.4: $t_{s}<t_{w}<t_{r}<M \leq T$ & Sub-case 3.4: $t_{s}<t_{r}<t_{w}<M \leq T$ \\
Sub-case 1.5: $t_{w}<t_{s}<t_{r}<T<M$ & Sub-case 2.5: $t_{s}<t_{w}<t_{r}<T<M$ & Sub-case 3.5: $t_{s}<t_{r}<t_{w}<T<M$ \\
\hline
\end{tabular}

$$
\begin{aligned}
& \mathrm{HC}_{o}=h_{o}\left\{\int_{0}^{t_{r}} I_{o}(t) d t+\int_{t_{r}}^{t_{w}} I_{o}(t) d t+\int_{t_{w}}^{T} I_{o}(t) d t\right\} \\
&= h_{o}\left\{\frac{w}{\alpha}(1-p)-\frac{D}{\alpha^{2}} \ln \left\{\frac{\alpha}{D}\left(w-w p e^{\alpha t_{w}}\right) e^{-\alpha t_{r}}\right.\right. \\
&+1\}\} .
\end{aligned}
$$

Hence, from Eqs. (27) and (28), we see that the holding costs in two cases with $t_{w}<t_{r}$ and $t_{r}<t_{w}$ are the same.

The interest earned, interest paid, and profit functions are calculated for different cases, which are shown in Table 1.

The solution procedure is as follows.

Case 1: $t_{w}<t_{s}<t_{r}$

Sub-case 1.1: $0<M \leq t_{w}<t_{s}<t_{r}$

The retailer earns interest on revenue generated from the sale of good quality items up to $M$. Although, the account must be paid at $M$ and for that, the money has to be arranged at some specified rate of interest in order to get remaining stocks financed for the period $M$ to $T$. The interest earned per cycle is equal to the area of triangle $O A M$ in Figure 6. The interest earned is:

$$
\frac{1}{2}(O M \times M A)=\frac{s I_{e} D M^{2}}{2} .
$$

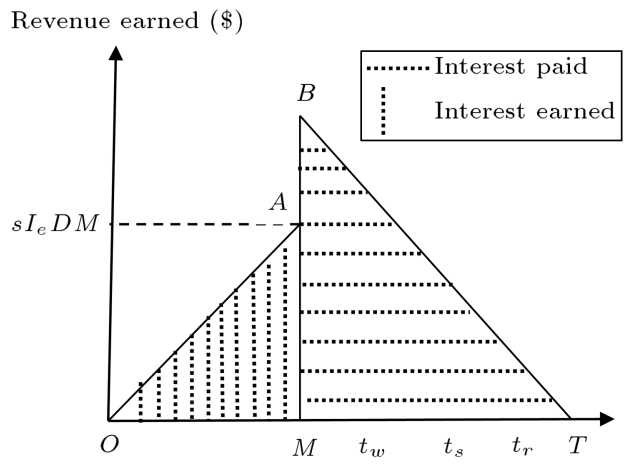

Figure 6. Graphical representation of interest earned and interest charged for $0<M \leq t_{w}<t_{s}<t_{r}$.

The interest payable per cycle for the inventory not sold after the due period $M$ from RW and OW is given by:

Interest paid from RW =

$$
\begin{aligned}
c I_{p} & \left\{\int_{M}^{t_{s}} I_{r}(t) d(t)+\int_{t_{s}}^{t_{r}} I_{r}(t) d(t)\right\} \\
= & c I_{p}\left\{\frac{D}{\beta}\left(M-t_{r}\right)\right. \\
& +\frac{1}{\beta}\left(y-w+\frac{D}{\beta}\right)\left(e^{-\beta M}-e^{-\beta t_{r}}\right) \\
& \left.+\frac{p}{\beta}(y-w) e^{\beta t_{s}}\left(e^{-\beta t_{r}}-e^{-\beta t_{s}}\right)\right\} .
\end{aligned}
$$

Interest paid from $\mathrm{OW}=$

$$
\begin{aligned}
c I_{p} & \left\{\int_{M}^{t_{w}} I_{o}(t) d t+\int_{t_{w}}^{t_{r}} I_{o}(t) d t+\int_{t_{r}}^{T} I_{o}(t) d t\right\} \\
= & c I_{p}\left\{\frac{w}{\alpha}\left(e^{-\alpha M}-p\right)\right. \\
& \left.-\frac{D}{\alpha^{2}} \ln \left\{\frac{\alpha}{D}\left(w-w p e^{\alpha t_{w}}\right) e^{-\alpha t_{r}}+1\right\}\right\} .
\end{aligned}
$$

Substituting the values of Eqs. (25)-(27) and (29)(31) into Eq. (24), the total profit for Sub-case 1.1 is obtained by Eq. (32) as shown in Box I.

\section{Sub-case 1.2: $t_{w}<M \leq t_{s}<t_{r}$}

The retailer receives interest on revenue created from the sale of good quality items up to $M$ and also from the defective items sold as a single lot from OW for $t_{w}<t \leq M$. The account has to be paid at $M$ and, hence, the retailer must arrange the money at a rate of interest in order to obtain the remaining stock financed from $M$ to $T$.

Therefore, the interest earned on good items per cycle is equal to the area of triangle $O A M$. Thus, the interest earned on good items is determined as $\frac{s I_{e} D M^{2}}{2}$. In addition, the retailer can earn interest on the sale 


$$
T P_{1.1}(y)=\left\{s D T+v y p+\frac{s I_{e} D M^{2}}{2}\right\}-\left\{\begin{array}{l}
k+c y+d y+h_{r}\left\{\frac{y-w}{\beta}(1-p)-\frac{D}{\beta^{2}}\left\{\ln \left(\frac{\beta}{D}(y-w)\left(1-p e^{\beta t_{s}}\right)+1\right)\right\}\right\} \\
+h_{o}\left\{\frac{w}{\alpha}(1-p)-\frac{D}{\alpha^{2}} \ln \left\{\frac{\alpha}{D}\left(w-w p e^{\alpha t_{w}}\right) e^{-\alpha t_{r}}+1\right\}\right\} \\
+c I_{p}\left\{\frac{D}{\beta}\left(M-t_{r}\right)+\frac{1}{\beta}\left(y-w+\frac{D}{\beta}\right)\left(e^{-\beta M}-e^{-\beta t_{r}}\right)\right. \\
\left.+\frac{p}{\beta}(y-w) e^{\beta t_{s}}\left(e^{-\beta t_{r}}-e^{-\beta t_{s}}\right)\right\} \\
+c I_{p}\left\{\frac{w}{\alpha}\left(e^{-\alpha M}-p\right)-\frac{D}{\alpha^{2}} \ln \left\{\frac{\alpha}{D}\left(w-w p e^{\alpha t_{w}}\right) e^{-\alpha t_{r}}+1\right\}\right\}
\end{array}\right\}
$$

Box I

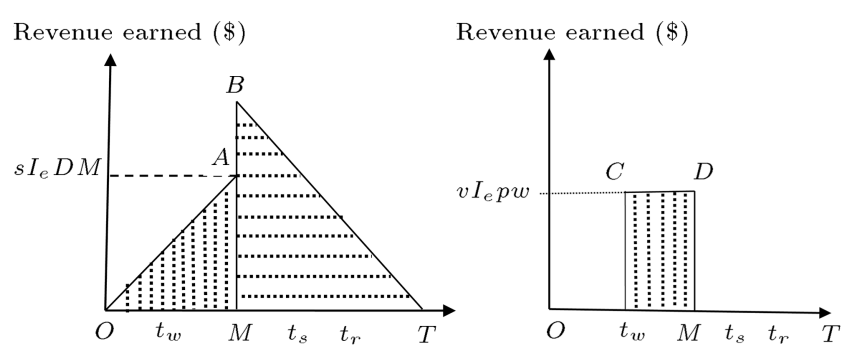

Figure 7. Graphical representation of interest earned and interest charged for $t_{w}<M \leq t_{s}<t_{r}$.

of defective items from OW, which is equal to the area of the rectangle $C D M t_{w}$, as shown in Figure 7. Therefore, the interest earned from the sale of defective items from $\mathrm{OW}$ is given by $v I_{e} p w\left(M-t_{w}\right)$ hence:

The total interest earned $=$

$$
\frac{s I_{e} D M^{2}}{2}+v I_{e} p w\left(M-t_{w}\right) \text {. }
$$

The interest payable per cycle for the inventory not sold after the due period $M$ from RW and OW is given by:

Interest paid from RW =

$$
\begin{aligned}
c I_{p}\left\{\int_{M}^{t_{s}} I_{r}(t) d(t)+\int_{t_{s}}^{t_{r}} I_{r}(t) d(t)\right\} \\
=c I_{p}\left\{\frac{D}{\beta}\left(M-t_{r}\right)\right. \\
+\frac{1}{\beta}\left(y-w+\frac{D}{\beta}\right)\left(e^{-\beta M}-e^{-\beta t_{r}}\right) \\
\left.+\frac{p}{\beta}(y-w) e^{\beta t_{s}}\left(e^{-\beta t_{r}}-e^{-\beta t_{s}}\right)\right\} .
\end{aligned}
$$

Interest paid from OW =

$$
\begin{aligned}
c I_{p} & \left\{\int_{M}^{t_{r}} I_{o}(t) d(t)+\int_{t_{r}}^{T} I_{o}(t) d(t)\right\} \\
= & c I_{p}\left\{\frac{w}{\alpha}\left(1-p e^{\alpha t_{w}}\right) e^{-\alpha M}\right. \\
& \left.-\frac{D}{\alpha^{2}} \ln \left\{\frac{\alpha w}{D}\left(1-p e^{\alpha t_{w}}\right) e^{-\alpha t_{r}}+1\right\}\right\} .
\end{aligned}
$$

Substituting the values from Eqs. (25)-(27) and (33)(35) in Eq. (24), the total profit for Sub-case 1.2 is obtained by Eq. (36) as shown in Box II.

Sub-case 1.3: $t_{w}<t_{s}<M \leq t_{r}$

In this sub-case, the retailer wins interest on revenue produced from the sale of good quality items up to $M$ and, likewise, from the sale of defective items wholesaled as one lot from OW for $t_{w}<t \leq M$ and from RW for $t_{s}<t \leq M$. The retailer has to arrange the money at a specified rate of interest to settle the account at $M$ in order to finance the remaining stocks for the period $M$ to $T$.

Therefore, the interest earned on good items per cycle is determined with the area of triangle $O A M$. Thus, the interest earned on good items is given by $\frac{s I_{e} D M^{2}}{2}$. Furthermore, the retailer can gain interest on the sale of defective items from OW and RW, which is equal to the sum of the areas of rectangles $C D M t_{w}$ and $E F M t_{s}$ that are depicted in Figure 8. Consequently, the interest earned from the sale of defective items from $\mathrm{OW}$ is $v I_{e} p w\left(M-t_{w}\right)$ and the interest earned from the sale of defective items from RW is $v I_{e} p(y-w)\left(M-t_{s}\right)$. Thus:

The total interest earned $=$ 


$$
\begin{aligned}
T P_{1.2}(y)=\left\{s D T+v y p+\frac{s I_{e} D M^{2}}{2}+v I_{e} p w\left(M-t_{w}\right)\right\} \\
\\
-\left\{\begin{array}{l}
k+c y+d y+h_{r}\left\{\frac{y-w}{\beta}(1-p)-\frac{D}{\beta^{2}}\left\{\ln \left(\frac{\beta}{D}(y-w)\left(1-p e^{\beta t_{s}}\right)+1\right)\right\}\right\} \\
+h_{o}\left\{\frac{w}{\alpha}(1-p)-\frac{D}{\alpha^{2}} \ln \left\{\frac{\alpha}{D}\left(w-w p e^{\alpha t_{w}}\right) e^{-\alpha t_{r}}+1\right\}\right\} \\
\left.+c I_{p}\left\{\frac{D}{\beta}\left(M-t_{r}\right)+\frac{1}{\beta}\left(y-w+\frac{D}{\beta}\right)\left(e^{-\beta M}-e^{-\beta t_{r}}\right)+\frac{p}{\beta}(y-w) e^{\beta t_{s}}\left(e^{-\beta t_{r}}-e^{-\beta t_{s}}\right)\right\}\right\} \\
+c I_{p}\left\{\frac{w}{\alpha}\left(1-p e^{\alpha t_{w}}\right) e^{-\alpha M}-\frac{D}{\alpha^{2}} \ln \left\{\frac{\alpha w}{D}\left(1-p e^{\alpha t_{w}}\right) e^{-\alpha t_{r}}+1\right\}\right\}
\end{array}\right\}
\end{aligned}
$$

Box II
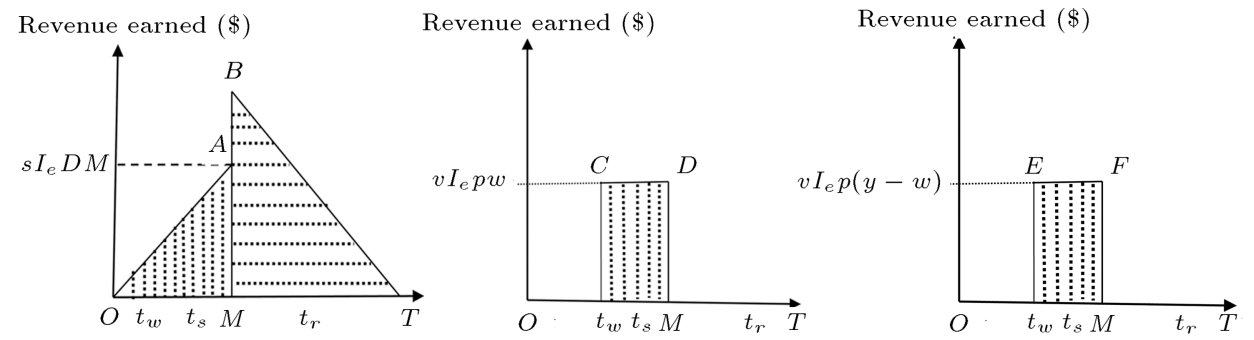

Figure 8. Graphical representation of interest earned and interest charged for $t_{w}<t_{s}<M \leq t_{r}$.

$$
\frac{s I_{e} D M^{2}}{2}+v I_{e} p(y-w)\left(M-t_{s}\right)+v I_{e} p w\left(M-t_{w}\right) .
$$

The interest payable per cycle for the inventory not sold after the due period $M$ from RW and OW is given by:

Interest paid from RW =

$$
\begin{aligned}
& c I_{p}\left\{\int_{M}^{t_{r}} I_{r}(t) d(t)\right\}=c I_{p}\left\{\frac{D}{\beta}\left(M-t_{r}\right)\right. \\
& \left.\quad+\frac{1}{\beta}\left((y-w)(1-p) e^{\beta t_{s}}+\frac{D}{\beta}\right)\left(e^{-\beta M}-e^{-\beta t_{r}}\right)\right\} .
\end{aligned}
$$

Interest paid from $\mathrm{OW}=$

$$
\begin{aligned}
c I_{p} & \left\{\int_{M}^{t_{r}} I_{o}(t) d(t)+\int_{t_{r}}^{T} I_{o}(t) d(t)\right\} \\
& =c I_{p}\left\{\frac{w}{\alpha}\left(1-p e^{\alpha t_{w}}\right) e^{-\alpha M}\right. \\
& \left.-\frac{D}{\alpha^{2}} \ln \left\{\frac{\alpha w}{D}\left(1-p e^{\alpha t_{w}}\right) e^{-\alpha t_{r}}+1\right\}\right\} .
\end{aligned}
$$

Substituting the values given in Eqs. (25)-(27) and
(37)-(39) into Eq. (24), the total profit for Sub-case 1.3 is obtained by Eq. (40) as shown in Box III.

\section{Sub-case 1.4: $t_{w}<t_{s}<t_{r}<M \leq T$}

The interest earned in this sub-case is calculated in the similar way to that in Sub-case 1.3. The interest earned on good items per cycle is obtained with the area of triangle $O A M$. Thus, the interest earned on good items is calculated with $\frac{s I_{e} D M^{2}}{2}$.

Additionally, the retailer obtains interest on the sale of defective items from both OW and RW, which is computed with the sum of the areas of rectangles $C D M t_{w}$ and EFMt $t_{s}$ that are displayed in Figure 9. Hence, the interest earned from the sale of defective items from $\mathrm{OW}$ is determined as $v I_{e} p w\left(M-t_{w}\right)$ and the interest earned from the sale of defective items from RW is obtained by $v I_{e} p(y-w)\left(M-t_{s}\right)$. Then:

The total interest earned $=$

$$
\frac{s I_{e} D M^{2}}{2}+v I_{e} p(y-w)\left(M-t_{s}\right)+v I_{e} p w\left(M-t_{w}\right) .
$$

The interest paid in this case will result only from OW, since RW is exhausted, and it is given by:

Interest paid from $\mathrm{OW}=$ 


$$
\begin{aligned}
T P_{1.3}(y)=\left\{s D T+v y p+\frac{s I_{e} D M^{2}}{2}+v I_{e} p(y-w)\left(M-t_{s}\right)+v I_{e} p w\left(M-t_{w}\right)\right\} \\
\\
-\left\{\begin{array}{l}
k+c y+d y+h_{r}\left\{\frac{y-w}{\beta}(1-p)-\frac{D}{\beta^{2}}\left\{\ln \left(\frac{\beta}{D}(y-w)\left(1-p e^{\beta t_{s}}\right)+1\right)\right\}\right\} \\
+h_{o}\left\{\frac{w}{\alpha}(1-p)-\frac{D}{\alpha^{2}} \ln \left\{\frac{\alpha}{D}\left(w-w p e^{\alpha t_{w}}\right) e^{-\alpha t_{r}}+1\right\}\right\} \\
+c I_{p}\left\{\frac{D}{\beta}\left(M-t_{r}\right)+\frac{1}{\beta}\left((y-w)(1-p) e^{\beta t_{s}}+\frac{D}{\beta}\right)\left(e^{-\beta M}-e^{-\beta t_{r}}\right)\right\} \\
+c I_{p}\left\{\frac{w}{\alpha}\left(1-p e^{\alpha t_{w}}\right) e^{-\alpha M}-\frac{D}{\alpha^{2}} \ln \left\{\frac{\alpha w}{D}\left(1-p e^{\alpha t_{w}}\right) e^{-\alpha t_{r}}+1\right\}\right\}
\end{array}\right\} .
\end{aligned}
$$

\section{Box III}
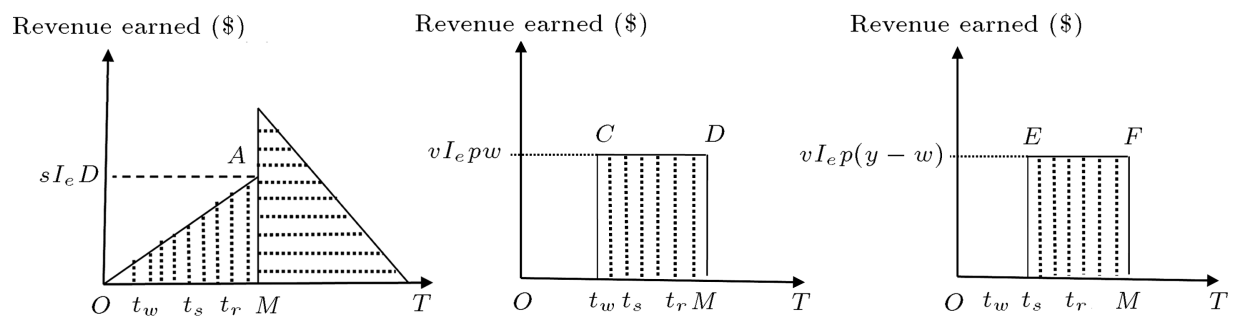

Figure 9. Graphical representation of interest earned and interest charged for $t_{w}<t_{s}<t_{r}<M \leq T$.

$$
\begin{aligned}
& c I_{p}\left\{\int_{M}^{T} I_{3 o}(t) d(t)\right\} \\
& \quad=c I_{p}\left\{\frac{D}{\alpha^{2}}\left(e^{\alpha(T-M)}-1\right)-\frac{D}{\alpha}(T-M)\right\} .
\end{aligned}
$$

Substituting Eqs. (25)-(27) and (40)-(42) into Eq. (24), the total profit for Sub-case 1.4 is obtained by Eq. (43) as shown in Box IV.

\section{Sub-case 1.5: $t_{w}<t_{s}<t_{r}<T<M$}

In this sub-case, the retailer obtains interest on revenue generated from the sale of good quality items up to $T$ for time $T<t \leq M$. Moreover, the retailer earns interest from the defective items vended as a sole lot from OW for $t_{w}<t \leq M$ and from RW for $t_{s}<t \leq M$.

The interest earned on good items per cycle is calculated with the area of triangle $A B T$. Also, the interest earned on good items for the period $[T, M]$ is computed with the area of the rectangle $C D M T$. Thus, the interest earned on good items is given by:

$$
\frac{s I_{e} D T^{2}}{2}+s I_{e} D T(M-T) .
$$

Besides, the retailer can obtain interest on the sale of defective items from OW and RW, which is determined with the sum of the areas of rectangles $C D M t_{w}$ and $E F M t_{s}$ as exposed in Figure 10.

$$
\begin{aligned}
T P_{1.4}(y)= & \left\{s D T+v y p+\frac{s I_{e} D M^{2}}{2}+v I_{e} p(y-w)\left(M-t_{s}\right)+v I_{e} p w\left(M-t_{w}\right)\right\} \\
& -\left\{\begin{array}{l}
k+c y+d y+h_{r}\left\{\frac{y-w}{\beta}(1-p)-\frac{D}{\beta^{2}}\left\{\ln \left(\frac{\beta}{D}(y-w)\left(1-p e^{\beta t_{s}}\right)+1\right)\right\}\right\} \\
+h_{o}\left\{\frac{w}{\alpha}(1-p)-\frac{D}{\alpha^{2}} \ln \left\{\frac{\alpha}{D}\left(w-w p e^{\alpha t_{w}}\right) e^{-\alpha t_{r}}+1\right\}\right\} \\
+c I_{p}\left\{\frac{D}{\alpha^{2}}\left(e^{\alpha(T-M)}-1\right)-\frac{D}{\alpha}(T-M)\right\}
\end{array}\right\} .
\end{aligned}
$$




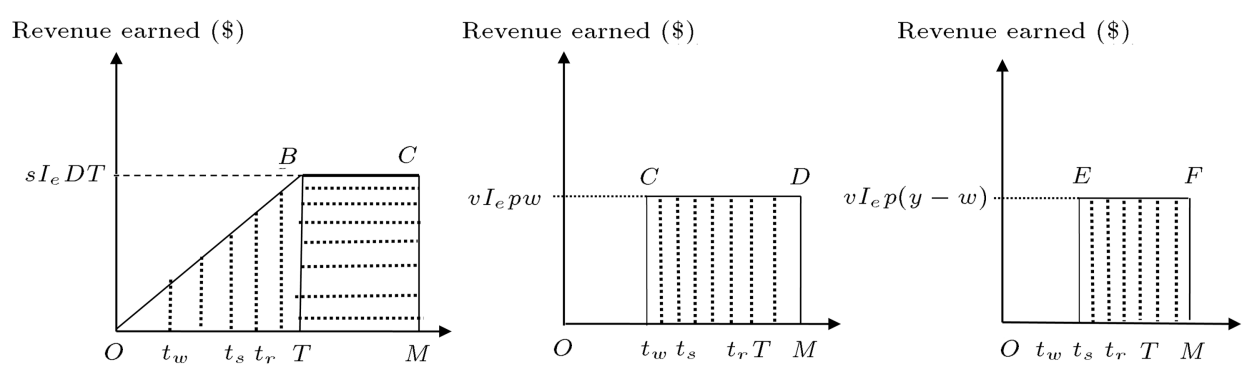

Figure 10. Graphical representation of interest earned and interest charged for $t_{w}<t_{s}<t_{r}<T<M$.

As a result, the interest earned from the sale of defective items from $\mathrm{OW}$ is calculated with $v I_{e} p w(M-$ $\left.t_{w}\right)$ and the interest earned from the sale of defective items from RW is computed with $v I_{e} p(y-w)\left(M-t_{s}\right)$. Hence:

Total interest earned $=$

$$
\begin{aligned}
\frac{s I_{e} D T^{2}}{2} & +s I_{e} D T(M-T)+v I_{e} p(y-w)\left(M-t_{s}\right) \\
& +v I_{e} p w\left(M-t_{w}\right) .
\end{aligned}
$$

Since no inventory is left after time $T$, the interest paid is equal to zero.

Substituting the values from Eqs. (25)-(27) and (44) into Eq. (24), the total profit for Sub-case 1.5 is obtained by Eq. (45) as shown in Box V.

\section{Case 2: $t_{s}<t_{w}<t_{r}$}

Sub-case 2.1: $0<M \leq t_{s}<t_{w}<t_{r}$

Here, the interest earned on good items is equal to the area of triangle $O A M$, which is shown in Figure 11. Thus:

The total interest earned $=$

$$
\frac{s I_{e} D M^{2}}{2} \text {. }
$$

The interest payable per cycle for the inventory not sold after the due period $M$ from RW and $\mathrm{OW}$ is given by:

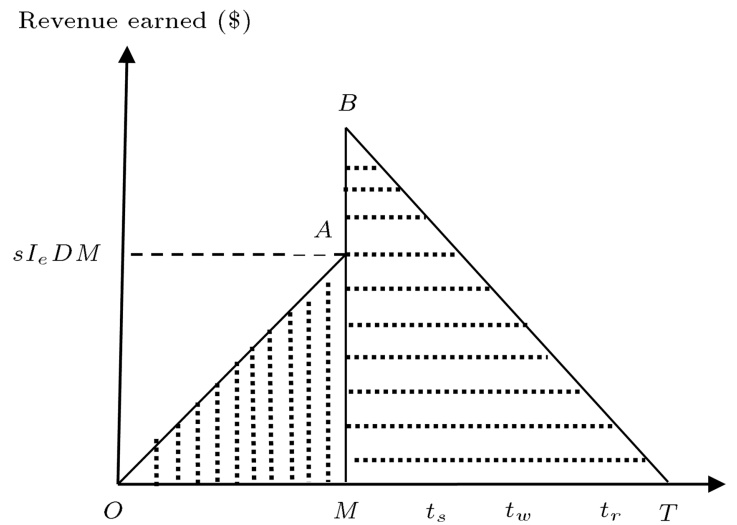

Figure 11. Graphical representation of interest earned and interest charged for $0<M \leq t_{s}<t_{w}<t_{r}$.

Interest paid from $\mathrm{RW}=$

$$
\begin{gathered}
c I_{p}\left\{\frac{D}{\beta}\left(M-t_{r}\right)+\frac{1}{\beta}\left(y-w+\frac{D}{\beta}\right)\left(e^{-\beta M}-e^{-\beta t_{r}}\right)\right. \\
\left.+\frac{p}{\beta}(y-w) e^{\beta t_{s}}\left(e^{-\beta t_{r}}-e^{-\beta t_{s}}\right)\right\}
\end{gathered}
$$

Interest paid from $\mathrm{OW}=$

$$
\begin{aligned}
c I_{p}\left\{\frac{w}{\alpha}\left(e^{-\alpha M}-p\right)\right. \\
\\
\left.\quad-\frac{D}{\alpha^{2}} \ln \left\{\frac{\alpha}{D}\left(w-w p e^{\alpha t_{w}}\right) e^{-\alpha t_{r}}+1\right\}\right\} .
\end{aligned}
$$

Substituting the values given in Eqs. (25)-(27)

$$
\begin{aligned}
T P_{1.5}(y)= & \left\{s D T+v y p+\frac{s I_{e} D T^{2}}{2}+s I_{e} D T(M-T)+v I_{e} p(y-w)\left(M-t_{s}\right)+v I_{e} p w\left(M-t_{w}\right)\right\} \\
& -\left\{\begin{array}{l}
\left.k+c y+d y+h_{r}\left\{\frac{y-w}{\beta}(1-p)-\frac{D}{\beta^{2}}\left\{\ln \left(\frac{\beta}{D}(y-w)\left(1-p e^{\beta t_{s}}\right)+1\right)\right\}\right\}\right) \\
+h_{o}\left\{\frac{w}{\alpha}(1-p)-\frac{D}{\alpha^{2}} \ln \left\{\frac{\alpha}{D}\left(w-w p e^{\alpha t_{w}}\right) e^{-\alpha t_{r}}+1\right\}\right\}
\end{array}\right\} .
\end{aligned}
$$




$$
\begin{aligned}
T P_{2.1}(y)=\left\{s D T+v y p+\frac{s I_{e} D M^{2}}{2}\right\} \\
\\
-\left\{\begin{array}{l}
k+c y+d y+h_{r}\left\{\frac{y-w}{\beta}(1-p)-\frac{D}{\beta^{2}}\left\{\ln \left(\frac{\beta}{D}(y-w)\left(1-p e^{\beta t_{s}}\right)+1\right)\right\}\right\} \\
+h_{o}\left\{\frac{w}{\alpha}(1-p)-\frac{D}{\alpha^{2}} \ln \left\{\frac{\alpha}{D}\left(w-w p e^{\alpha t_{w}}\right) e^{-\alpha t_{r}}+1\right\}\right\} \\
+c I_{p}\left\{\frac{D}{\beta}\left(M-t_{r}\right)+\frac{1}{\beta}\left(y-w+\frac{D}{\beta}\right)\left(e^{-\beta M}-e^{-\beta t_{r}}\right)+\frac{p}{\beta}(y-w) e^{\beta t_{s}}\left(e^{-\beta t_{r}}-e^{-\beta t_{s}}\right)\right\} \\
+c I_{p}\left\{\frac{w}{\alpha}\left(e^{-\alpha M}-p\right)-\frac{D}{\alpha^{2}} \ln \left\{\frac{\alpha}{D}\left(w-w p e^{\alpha t_{w}}\right) e^{-\alpha t_{r}}+1\right\}\right\}
\end{array}\right\}
\end{aligned}
$$

Box VI

and (46)-(48) into Eq. (24), the total profit for Subcase 2.1 is obtained by Eq. (49) as shown in Box VI.

Sub-case 2.2: $t_{s}<M \leq t_{w}<t_{r}$

Here, the interest earned on good items per cycle is determined by the area of triangle $O A M$. Therefore, the interest earned on good items is $\frac{s I_{e} D M^{2}}{2}$. Furthermore, the retailer can gain interest on the sale of defective items from RW, which is given by the area of rectangle $C D M t_{s}$ as shown in Figure 12. Hence, the interest earned from the sale of defective items from RW is $v I_{e} p(y-w)\left(M-t_{s}\right)$. Thus:

Total interest earned $=$

$$
\frac{s I_{e} D M^{2}}{2}+v I_{e} p(y-w)\left(M-t_{s}\right) \text {. }
$$

Similarly, the interest payable per cycle for the inventory not sold after the due period $M$ from RW and OW is given by:

Interest paid from $\mathrm{RW}=$

$$
\begin{aligned}
c I_{p}\{ & \frac{D}{\beta}\left(M-t_{r}\right) \\
& \left.+\frac{1}{\beta}\left((y-w)(1-p) e^{\beta t_{s}}+\frac{D}{\beta}\right)\left(e^{-\beta M}-e^{-\beta t_{r}}\right)\right\}
\end{aligned}
$$

Interest paid from $\mathrm{OW}=\%$ pagebreak $[3]$

$$
\begin{aligned}
c I_{p} & \left\{\frac{w}{\alpha}\left(e^{-\alpha M}-p\right)\right. \\
& \left.-\frac{D}{\alpha^{2}} \ln \left\{\frac{\alpha}{D}\left(w-w p e^{\alpha t_{w}}\right) e^{-\alpha t_{r}}+1\right\}\right\} .
\end{aligned}
$$

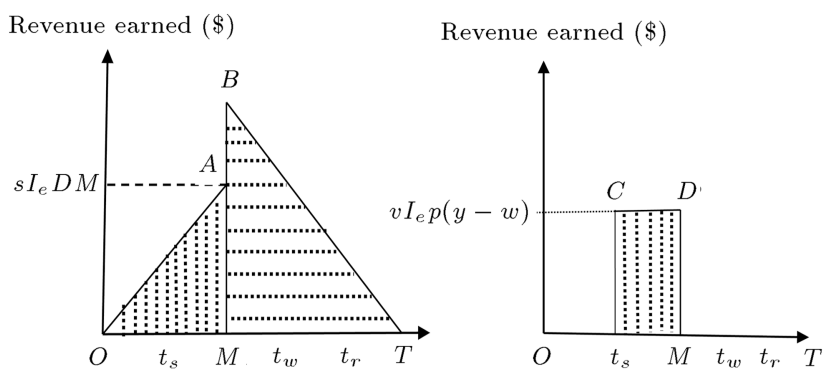

Figure 12. Graphical representation of interest earned and interest charged for $t_{s}<M \leq t_{w}<t_{r}$.

Substituting Eqs. (25)-(27) and (50)-(52) in Eq. (24), the total profit for Sub-case 2.2 is obtained by Eq. (53) as shown in Box VII.

\section{Sub-case 2.3: $t_{s}<t_{w}<M \leq t_{r}$}

Here, the interest earned on good items per cycle is computed by the area of triangle $O A M$. Thus, the interest earned on good items is $\frac{s I_{e} D M^{2}}{2}$. Besides, the retailer earns interest on the sale of defective items from RW and OW, which is equal to the sum of the areas of rectangles $E F M t_{w}$ and $C D M t_{s}$ as shown in Figure 13. Consequently, the interest earned from the sale of defective items from OW and RW is calculated with $v I_{e} p w\left(M-t_{w}\right)$ and $v I_{e} p(y-w)\left(M-t_{s}\right)$, respectively. Thus:

The total interest earned $=$

$$
\frac{s I_{e} D M^{2}}{2}+v I_{e} p(y-w)\left(M-t_{s}\right)+v I_{e} p w\left(M-t_{w}\right) .
$$

The interest payable per cycle for the inventory not sold after the due period $M$ from RW and $\mathrm{OW}$ is given by:

Interest paid from RW $=$ 


$$
\begin{aligned}
T P_{2.2}(y)=\left\{s D T+v y p+\frac{s I_{e} D M^{2}}{2}+v I_{e} p(y-w)\left(M-t_{s}\right)\right\} \\
\\
-\left\{\begin{array}{l}
k+c y+d y+h_{r}\left\{\frac{y-w}{\beta}(1-p)-\frac{D}{\beta^{2}}\left\{\ln \left(\frac{\beta}{D}(y-w)\left(1-p e^{\beta t_{s}}\right)+1\right)\right\}\right\} \\
+h_{o}\left\{\frac{w}{\alpha}(1-p)-\frac{D}{\alpha^{2}} \ln \left\{\frac{\alpha}{D}\left(w-w p e^{\alpha t_{w}}\right) e^{-\alpha t_{r}}+1\right\}\right\} \\
c I_{p}\left\{\frac{D}{\beta}\left(M-t_{r}\right)+\frac{1}{\beta}\left((y-w)(1-p) e^{\beta t_{s}}+\frac{D}{\beta}\right)\left(e^{-\beta M}-e^{-\beta t_{r}}\right)\right\} \\
+c I_{p}\left\{\frac{w}{\alpha}\left(e^{-\alpha M}-p\right)-\frac{D}{\alpha^{2}} \ln \left\{\frac{\alpha}{D}\left(w-w p e^{\alpha t_{w}}\right) e^{-\alpha t_{r}}+1\right\}\right\}
\end{array}\right\} .
\end{aligned}
$$

\section{Box VII}

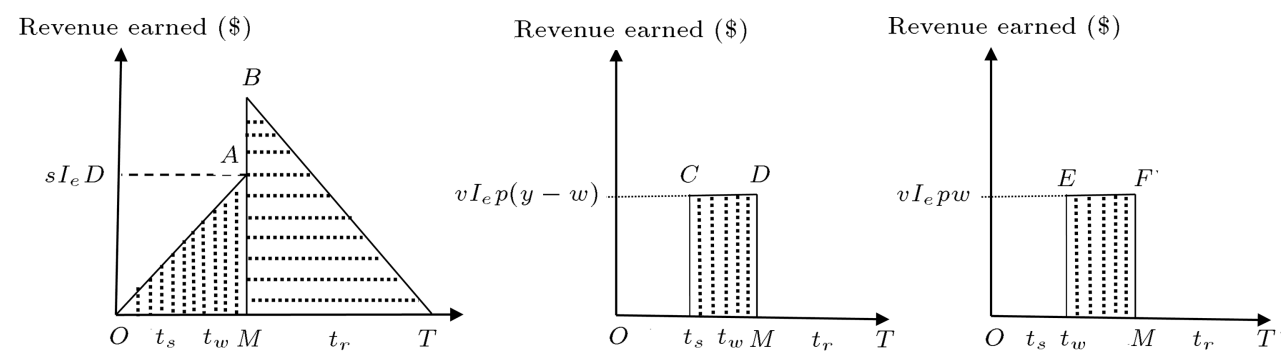

Figure 13. Graphical representation of interest earned and interest charged for $t_{s}<t_{w}<M \leq t_{r}$.
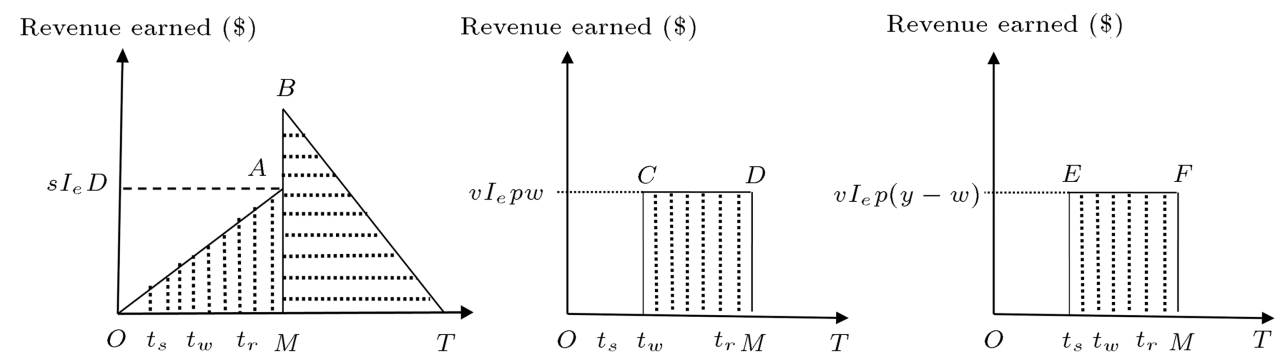

Figure 14. Graphical representation of interest earned and interest charged for $t_{s}<t_{w}<t_{r}<M \leq T$.

$$
\begin{aligned}
c I_{p} & \left\{\frac{D}{\beta}\left(M-t_{r}\right)\right. \\
& \left.+\frac{1}{\beta}\left((y-w)(1-p) e^{\beta t_{s}}+\frac{D}{\beta}\right)\left(e^{-\beta M}-e^{-\beta t_{r}}\right)\right\} .
\end{aligned}
$$

Interest paid from $\mathrm{OW}=$

$$
\begin{aligned}
c I_{p}\left\{\frac{w}{\alpha}\left(1-p e^{\alpha t_{w}}\right) e^{-\alpha M}\right. \\
\left.\quad-\frac{D}{\alpha^{2}} \ln \left\{\frac{\alpha w}{D}\left(1-p e^{\alpha t_{w}}\right) e^{-\alpha t_{r}}+1\right\}\right\} .
\end{aligned}
$$

Substituting the values from Eqs. (25)-(27) and (54)(56) in Eq. (24), the total profit for Sub-case 2.3 is obtained by Eq. (57) as shown in Box VIII.

\section{Sub-case 2.4: $t_{s}<t_{w}<t_{r}<M \leq T$}

The interest earned in this sub-case is calculated in an analogous manner like that in Sub-case 2.3, which is shown in Figure 14. Hence:

Total interest earned $=$

$$
\frac{s I_{e} D M^{2}}{2}+v I_{e} p(y-w)\left(M-t_{s}\right)+v I_{e} p w\left(M-t_{w}\right) .
$$

Since RW is exhausted at $t_{r}$, the interest paid occurs by the inventory not sold from OW and is given as:

Interest paid from $\mathrm{OW}=$

$$
c I_{p}\left\{\frac{D}{\alpha^{2}}\left(e^{\alpha(T-M)}-1\right)-\frac{D}{\alpha}(T-M)\right\} .
$$




$$
\begin{aligned}
T P_{2.3}(y)=\left\{s D T+v y p+\frac{s I_{e} D M^{2}}{2}+v I_{e} p(y-w)\left(M-t_{s}\right)+v I_{e} p w\left(M-t_{w}\right)\right\} \\
\\
-\left\{\begin{array}{l}
k+c y+d y+h_{r}\left\{\frac{y-w}{\beta}(1-p)-\frac{D}{\beta^{2}}\left\{\ln \left(\frac{\beta}{D}(y-w)\left(1-p e^{\beta t_{s}}\right)+1\right)\right\}\right\} \\
+h_{o}\left\{\frac{w}{\alpha}(1-p)-\frac{D}{\alpha^{2}} \ln \left\{\frac{\alpha}{D}\left(w-w p e^{\alpha t_{w}}\right) e^{-\alpha t_{r}}+1\right\}\right\} \\
+c I_{p}\left\{\frac{D}{\beta}\left(M-t_{r}\right)+\frac{1}{\beta}\left((y-w)(1-p) e^{\beta t_{s}}+\frac{D}{\beta}\right)\left(e^{-\beta M}-e^{-\beta t_{r}}\right)\right\} \\
+c I_{p}\left\{\frac{w}{\alpha}\left(1-p e^{\alpha t_{w}}\right) e^{-\alpha M}-\frac{D}{\alpha^{2}} \ln \left\{\frac{\alpha w}{D}\left(1-p e^{\alpha t_{w}}\right) e^{-\alpha t_{r}}+1\right\}\right\}
\end{array}\right\} .
\end{aligned}
$$

\section{Box VIII}

$$
\begin{aligned}
T P_{2.4}(y)= & \left\{s D T+v y p+\frac{s I_{e} D M^{2}}{2}+v I_{e} p(y-w)\left(M-t_{s}\right)+v I_{e} p w\left(M-t_{w}\right)\right\} \\
& -\left\{\begin{array}{l}
k+c y+d y+h_{r}\left\{\frac{y-w}{\beta}(1-p)-\frac{D}{\beta^{2}}\left\{\ln \left(\frac{\beta}{D}(y-w)\left(1-p e^{\beta t_{s}}\right)+1\right)\right\}\right\} \\
+h_{o}\left\{\frac{w}{\alpha}(1-p)-\frac{D}{\alpha^{2}} \ln \left\{\frac{\alpha}{D}\left(w-w p e^{\alpha t_{w}}\right) e^{-\alpha t_{r}}+1\right\}\right\} \\
+c I_{p}\left\{\frac{D}{\alpha^{2}}\left(e^{\alpha(T-M)}-1\right)-\frac{D}{\alpha}(T-M)\right\}
\end{array}\right\} .
\end{aligned}
$$

Box IX

Substituting Eqs. (25)-(27) and (58)-(59) into Eq. (24), the total profit for Sub-case 2.4 is obtained by Eq. (60) as shown in Box IX.

\section{Sub-case 2.5: $t_{s}<t_{w}<t_{r}<T<M$}

Here, the interest obtained on good items per cycle is computed by the area of triangle $O B T$. Also, the interest gained on good items from the period $[T, M]$ is calculated by the area of the rectangle BCMT. Hence, the interest gained on good items is determined with:

$$
\frac{s I_{e} D T^{2}}{2}+s I_{e} D T(M-T) \text {. }
$$

In addition, the retailer can get interest on the sale of defective items from OW and RW, which is equal to sum of the areas of rectangles $C D M t_{w}$ and $E F M t_{s}$ that are displayed in Figure 15. Therefore, the interest earned from the sale of defective items from OW is $v I_{e} p w\left(M-t_{w}\right)$ and the interest earned from the sale of
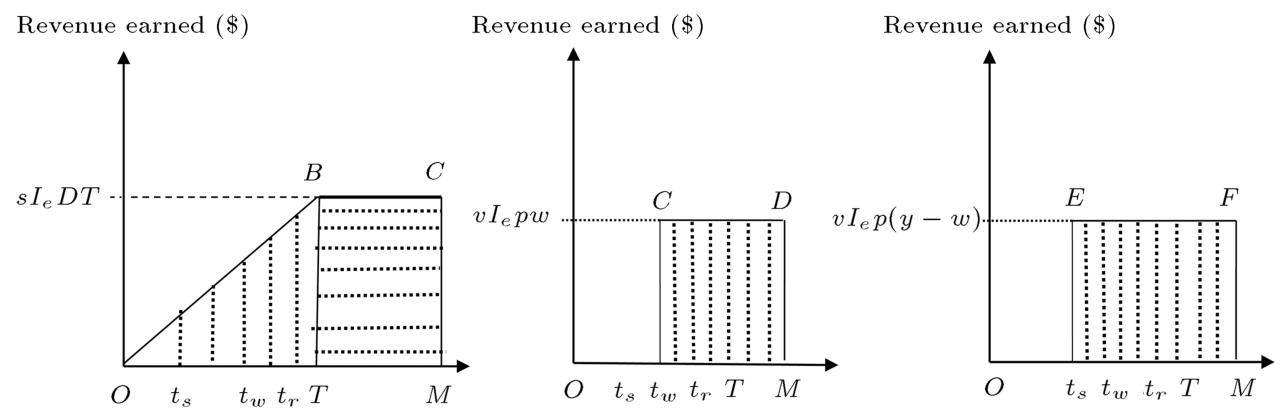

Figure 15. Graphical representation of interest earned and interest charged for $t_{s}<t_{w}<t_{r}<T<M$. 
defective items from RW is $v I_{e} p(y-w)\left(M-t_{s}\right)$. Thus:

Total interest earned $=$

$$
\begin{aligned}
\frac{s I_{e} D T^{2}}{2} & +s I_{e} D T(M-T)+v I_{e} p(y-w)\left(M-t_{s}\right) \\
& +v I_{e} p w\left(M-t_{w}\right) .
\end{aligned}
$$

As the inventory gets exhausted at time $T$, the interest paid is zero.

Substituting the values given in Eqs. (25)-(27) and (61) in Eq. (24), the total profit for Sub-case 2.5 is obtained by Eq. (62) as shown in Box X.

Case 3: $t_{s}<t_{r}<t_{w}$

Sub-case 3.1: $0<M \leq t_{s}<t_{r}<t_{w}$

The retailer gains interest on the revenue caused by the sale of good quality items up to $M$, which is presented in Figure 16. Although, the account must be paid at $M$ and for that, the money must be arranged at a specified rate of interest in order to obtain a financing for the remaining stocks for the period $M$ to $T$. Therefore:

The interest earned on good items $=$

$$
\frac{s I_{e} D M^{2}}{2}
$$

Similarly, the interest payable per cycle for the inventory not sold after the due period $M$ from RW and OW is given by:

Interest paid from RW =

$$
\begin{gathered}
c I_{p}\left\{\frac{D}{\beta}\left(M-t_{r}\right)+\frac{1}{\beta}\left(y-w+\frac{D}{\beta}\right)\left(e^{-\beta M}-e^{-\beta t_{r}}\right)\right. \\
\left.+\frac{p}{\beta}(y-w) e^{\beta t_{s}}\left(e^{-\beta t_{r}}-e^{-\beta t_{s}}\right)\right\} .
\end{gathered}
$$

Interest paid from $\mathrm{OW}=$

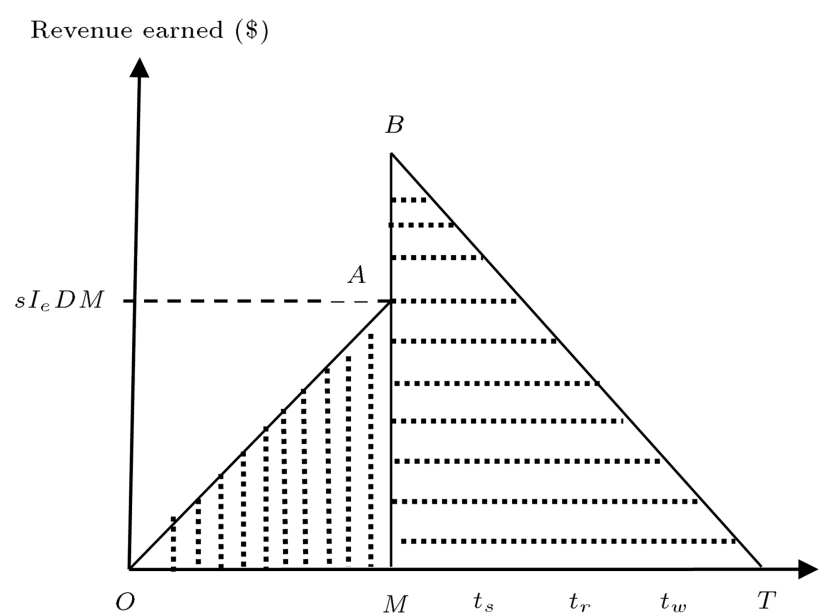

Figure 16. Graphical representation of interest earned and interest charged for $0<M \leq t_{s}<t_{r}<t_{w}$.

$$
\begin{aligned}
c I_{p}\left\{\frac{w}{\alpha}\left(e^{-\alpha M}-p\right)\right. \\
\left.\quad-\frac{D}{\alpha^{2}} \ln \left\{\frac{\alpha w}{D}\left(1-p e^{\alpha t_{w}}\right) e^{-\alpha t_{r}}+1\right\}\right\} .
\end{aligned}
$$

Substituting the values from Eqs. (25)-(27) and (63)(65) in Eq. (24), the total profit for Sub-case 3.1 is obtained by Eq. (66) as shown in Box XI.

Sub-case 3.2: $t_{s}<M \leq t_{r}<t_{w}$

The interest gained on good items per cycle is obtained with the area of triangle $O A M$. Thus, the interest gained on good items is $\frac{s I_{e} D M^{2}}{2}$. Additionally, the retailer can win interest on the sale of defective items from RW, which is determined with the area of rectangle $C D M t_{s}$ that is illustrated in Figure 17.

Thus, the interest earned from the sale of defective items from $\mathrm{RW}$ is $v I_{e} p(y-w)\left(M-t_{s}\right)$.

Interest earned $=$

$$
\frac{s I_{e} D M^{2}}{2}+v I_{e} p(y-w)\left(M-t_{s}\right)
$$

Also, the interest payable per cycle for the inventory

$$
\begin{aligned}
T P_{2.5}(y)= & \left\{s D T+v y p+\frac{s I_{e} D T^{2}}{2}+s I_{e} D T(M-T)+v I_{e} p(y-w)\left(M-t_{s}\right)+v I_{e} p w\left(M-t_{w}\right)\right\} \\
& -\left\{\begin{array}{l}
k+c y+d y+h_{r}\left\{\frac{y-w}{\beta}(1-p)-\frac{D}{\beta^{2}}\left\{\ln \left(\frac{\beta}{D}(y-w)\left(1-p e^{\beta t_{s}}\right)+1\right)\right\}\right\} \\
+h_{o}\left\{\frac{w}{\alpha}(1-p)-\frac{D}{\alpha^{2}} \ln \left\{\frac{\alpha}{D}\left(w-w p e^{\alpha t_{w}}\right) e^{-\alpha t_{r}}+1\right\}\right\}
\end{array}\right\} .
\end{aligned}
$$




$$
\begin{aligned}
T P_{3.1}(y)=\left\{s D T+v y p+\frac{s I_{e} D M^{2}}{2}\right\} \\
\\
-\left\{\begin{array}{l}
k+c y+d y+h_{r}\left\{\frac{y-w}{\beta}(1-p)-\frac{D}{\beta^{2}}\left\{\ln \left(\frac{\beta}{D}(y-w)\left(1-p e^{\beta t_{s}}\right)+1\right)\right\}\right\} \\
+h_{o}\left\{\frac{w}{\alpha}(1-p)-\frac{D}{\alpha^{2}} \ln \left\{\frac{\alpha}{D}\left(w-w p e^{\alpha t_{w}}\right) e^{-\alpha t_{r}}+1\right\}\right\} \\
\left.\left.+c I_{p}\left\{\frac{D}{\beta}\left(M-t_{r}\right)+\frac{1}{\beta}\left(y-w+\frac{D}{\beta}\right)\left(e^{-\beta M}-e^{-\beta t_{r}}\right)+\frac{p}{\beta}(y-w) e^{\beta t_{s}}\left(e^{-\beta t_{r}}-e^{-\beta t_{s}}\right)\right\}\right\}(66)\right\} \\
+c I_{p}\left\{\frac{w}{\alpha}\left(e^{-\alpha M}-p\right)-\frac{D}{\alpha^{2}} \ln \left\{\frac{\alpha w}{D}\left(1-p e^{\alpha t_{w}}\right) e^{-\alpha t_{r}}+1\right\}\right\}
\end{array}\right\}
\end{aligned}
$$

Box XI

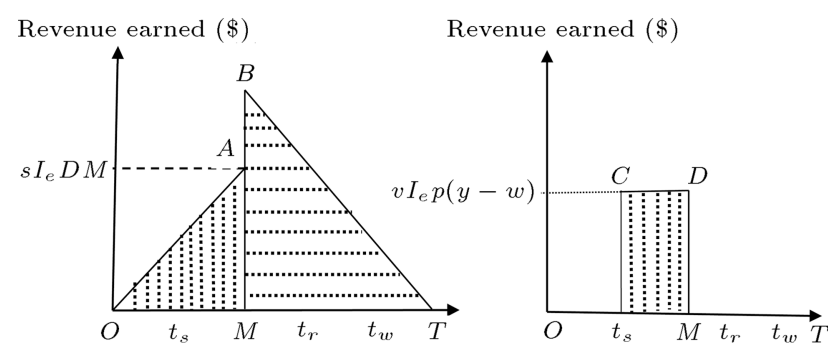

Figure 17. Graphical representation of interest earned and interest charged for $t_{s}<M \leq t_{r}<t_{w}$.

not sold after the due period $M$ from RW and OW is given by:

Interest paid from RW =

$$
\begin{aligned}
c I_{p}\{ & \frac{D}{\beta}\left(M-t_{r}\right) \\
& \left.+\frac{1}{\beta}\left((y-w)(1-p) e^{\beta t_{s}}+\frac{D}{\beta}\right)\left(e^{-\beta M}-e^{-\beta t_{r}}\right)\right\} .
\end{aligned}
$$

Interest paid from $\mathrm{OW}=$

$$
\begin{aligned}
c I_{p}\left\{\frac{w}{\alpha}\left(e^{-\alpha M}-p\right)\right. \\
\left.\quad-\frac{D}{\alpha^{2}} \ln \left\{\frac{\alpha w}{D}\left(1-p e^{\alpha t_{w}}\right) e^{-\alpha t_{r}}+1\right\}\right\} .
\end{aligned}
$$

Substituting the values from Eqs. (25)-(27) and (67)(69) in Eq. (24), the total profit for Sub-case 3.2 is obtained by Eq. (70) as shown in Box XII.

\section{Sub-case 3.3: $t_{s}<t_{r}<M \leq t_{w}$}

The interest gained in this sub-case is calculated in the same way as that in Sub-case 3.2 (see Figure 18). Thaus:

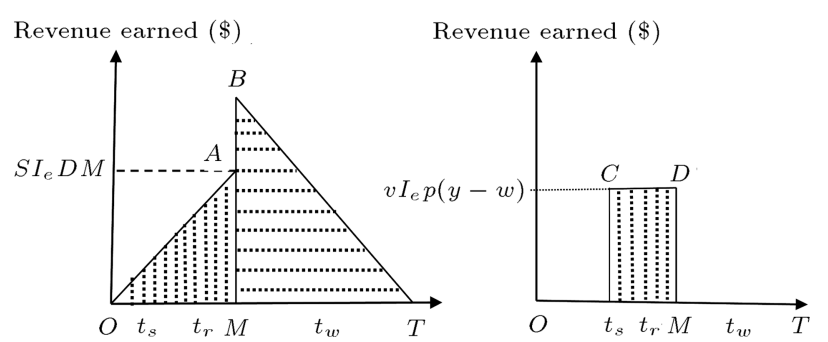

Figure 18. Graphical representation of interest earned and interest charged for $t_{s}<t_{r}<M \leq t_{w}$.

The total interest earned $=$

$$
\frac{s I_{e} D M^{2}}{2}+v I_{e} p(y-w)\left(M-t_{s}\right) .
$$

The RW is exhausted at time $t_{r}$; therefore, the interest to be paid occurs only due to the inventory left from OW and is given by:

Interest paid from $\mathrm{OW}=$

$$
\begin{gathered}
c I_{p}\left\{\frac{D}{\alpha}(M-T)+\frac{w}{\alpha}\left(e^{-\alpha M}-p\right)\right. \\
\left.+\frac{D}{\alpha^{2}}\left(e^{-\alpha\left(M-t_{r}\right)}-1\right)\right\} .
\end{gathered}
$$

Substituting the values from Eqs. (25)-(27) and (71)(72) in Eq. (24), the total profit for Sub-case 3.3 is obtained by Eq. (73) as shown in Box XIII.

\section{Sub-case 3.4: $t_{s}<t_{r}<t_{w}<M \leq T$}

The interest earned on good items per cycle is calculated with the area of triangle $O A M$. As a result, the interest earned on good items is $\frac{s I_{e} D M^{2}}{2}$. As well, the retailer can get interest on the sale of defective items from RW and OW, which is determined with the sum of the areas of rectangles $C D M t_{w}$ and $E F M t_{s}$ 


$$
\begin{aligned}
T P_{3.2}(y)=\left\{s D T+v y p+\frac{s I_{e} D M^{2}}{2}+v I_{e} p(y-w)\left(M-t_{s}\right)\right\} \\
\\
-\left\{\begin{array}{l}
k+c y+d y+h_{r}\left\{\frac{y-w}{\beta}(1-p)-\frac{D}{\beta^{2}}\left\{\ln \left(\frac{\beta}{D}(y-w)\left(1-p e^{\beta t_{s}}\right)+1\right)\right\}\right\} \\
+h_{o}\left\{\frac{w}{\alpha}(1-p)-\frac{D}{\alpha^{2}} \ln \left\{\frac{\alpha}{D}\left(w-w p e^{\alpha t_{w}}\right) e^{-\alpha t_{r}}+1\right\}\right\} \\
\left.+c I_{p}\left\{\frac{D}{\beta}\left(M-t_{r}\right)+\frac{1}{\beta}\left((y-w)(1-p) e^{\beta t_{s}}+\frac{D}{\beta}\right)\left(e^{-\beta M}-e^{-\beta t_{r}}\right)\right\}\right\} \\
+c I_{p}\left\{\frac{w}{\alpha}\left(e^{-\alpha M}-p\right)-\frac{D}{\alpha^{2}} \ln \left\{\frac{\alpha w}{D}\left(1-p e^{\alpha t_{w}}\right) e^{-\alpha t_{r}}+1\right\}\right\}
\end{array}\right\} .
\end{aligned}
$$

\section{Box XII}

$$
\begin{aligned}
T P_{3.3}(y)= & \left\{s D+v y p+\frac{s I_{e} D M^{2}}{2}+v I_{e} p(y-w)\left(M-t_{s}\right)\right\} \\
& -\left\{\begin{array}{l}
k+c y+d y+h_{r}\left\{\frac{y-w}{\beta}(1-p)-\frac{D}{\beta^{2}}\left\{\ln \left(\frac{\beta}{D}(y-w)\left(1-p e^{\beta t_{s}}\right)+1\right)\right\}\right\} \\
+h_{o}\left\{\frac{w}{\alpha}(1-p)-\frac{D}{\alpha^{2}} \ln \left\{\frac{\alpha}{D}\left(w-w p e^{\alpha t_{w}}\right) e^{-\alpha t_{r}}+1\right\}\right\} \\
+c I_{p}\left\{\frac{D}{\alpha}(M-T)+\frac{w}{\alpha}\left(e^{-\alpha M}-p\right)+\frac{D}{\alpha^{2}}\left(e^{-\alpha\left(M-t_{r}\right)}-1\right)\right\}
\end{array}\right\} .
\end{aligned}
$$

Box XIII

that are portrayed in Figure 19. Hence, the interest received from the sale of defective items from $\mathrm{OW}$ is $v I_{e} p w\left(M-t_{w}\right)$ and the interest gotten from the sale of defective items from $\mathrm{RW}=v I_{e} p(y-w)\left(M-t_{s}\right)$. As a result:

The interest earned $=$

$$
\frac{s I_{e} D M^{2}}{2}+v I_{e} p(y-w)\left(M-t_{s}\right)+v I_{e} p w\left(M-t_{w}\right) \text {. }
$$

The interest payable per cycle for the inventory not sold after the due period $M$ from $\mathrm{OW}$ is given by: Interest paid from $\mathrm{OW}=$

$$
\begin{aligned}
& c I_{p}\left\{\frac{D}{\alpha}(M-T)+\frac{1}{\alpha}\left(w e^{-\alpha t_{r}}+\frac{D}{\alpha}\right.\right. \\
&\left.\left.-p w e^{\alpha\left(t_{w}-t_{r}\right)}\right)\left(e^{-\alpha\left(M-t_{r}\right)}-e^{-\alpha\left(T-t_{r}\right)}\right)\right\} .
\end{aligned}
$$

Substituting the values from Eqs. (25)-(27) and (74)-
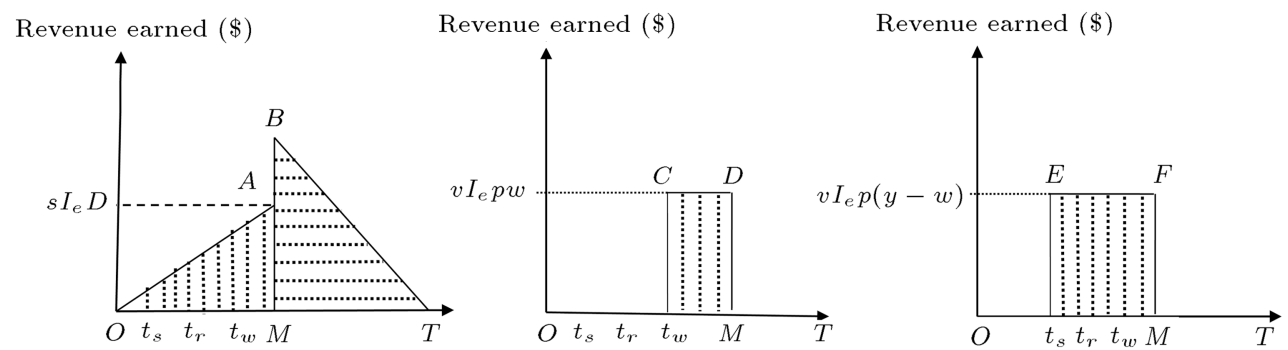

Figure 19. Graphical representation of interest earned and interest charged for $t_{s}<t_{r}<t_{w}<M \leq T$. 


$$
\begin{aligned}
T P_{3.4}(y)= & \left\{s D T+v y p+\frac{s I_{e} D M^{2}}{2}+v I_{e} p(y-w)\left(M-t_{s}\right)+v I_{e} p w\left(M-t_{w}\right)\right\} \\
& -\left\{\begin{array}{l}
k+c y+d y+h_{r}\left\{\frac{y-w}{\beta}(1-p)-\frac{D}{\beta^{2}}\left\{\ln \left(\frac{\beta}{D}(y-w)\left(1-p e^{\beta t_{s}}\right)+1\right)\right\}\right\} \\
+h_{o}\left\{\frac{w}{\alpha}(1-p)-\frac{D}{\alpha^{2}} \ln \left\{\frac{\alpha}{D}\left(w-w p e^{\alpha t_{w}}\right) e^{-\alpha t_{r}}+1\right\}\right\} \\
+c I_{p}\left\{\frac{D}{\alpha}(M-T)+\frac{1}{\alpha}\left(w e^{-\alpha t_{r}}+\frac{D}{\alpha}-p w e^{\alpha\left(t_{w}-t_{r}\right)}\right)\left(e^{-\alpha\left(M-t_{r}\right)}-e^{-\alpha\left(T-t_{r}\right)}\right)\right\}
\end{array}\right\}
\end{aligned}
$$

(75) in Eq. (24), the total profit for the Sub-case 3.4 is obtained by Eq. (76) as shown in Box XIV.

\section{Sub-case 3.5: $t_{s}<t_{r}<t_{w}<T<M$}

Here, the interest acquired on good items per cycle is obtained with the area of triangle $O B T$. Likewise, the interest gained on good items for the period $[T, M]$ is given by the area of rectangle $B C M T$. Consequently, the interest received on good items is:

$$
\frac{s I_{e} D T^{2}}{2}+s I_{e} D T(M-T) .
$$

In addition, the retailer can gain interest on the sale of defective items from OW and RW, which is equal to the sum of the areas of rectangles $D C M t_{w}$ and $E F M t_{s}$ as shown in Figure 20. Therefore, the interest earned from the sale of defective items from OW is determined with $v I_{e} p w\left(M-t_{w}\right)$ and the interest received from the sale of defective items from RW is obtained with $v I_{e} p(y-$ $w)\left(M-t_{s}\right)$. Thus:

Total interest earned $=$

$$
\begin{aligned}
\frac{s I_{e} D T^{2}}{2} & +s I_{e} D T(M-T)+v I_{e} p(y-w)\left(M-t_{s}\right) \\
& +v I_{e} p w\left(M-t_{w}\right) .
\end{aligned}
$$

As the inventory gets exhausted at $T$, the interest paid is equal to zero.
Substituting the values from Eqs. (25)-(27) and (77) in Eq. (24), the total profit for Sub-case 3.5 is obtained by Eq. (78) as shown in Box XV. From all different equations of profit functions, it is found that:

From Eqs. (32), (50), and (68):

$$
T P_{1.1}(y)=T P_{2.1}(y)=T P_{3.1}(y),
$$

From Eqs. (40) and (58):

$$
T P_{1.3}(y)=T P_{2.3}(y),
$$

From Eqs. (43) and (61):

$$
T P_{1.4}(y)=T P_{2.4}(y),
$$

From Eqs. (46), (64), and (81):

$$
T P_{1.5}(y)=T P_{2.5}(y)=T P_{3.5}(y),
$$

From Eqs. (54) and (72):

$$
T P_{2.2}(y)=T P_{3.2}(y) \text {. }
$$

Hence, eight different cases exist for the retailer's profit per cycle, which can be expressed as:

$$
\begin{aligned}
& \operatorname{TPU}(y)= \\
& \operatorname{TPU}_{1}(y)=\operatorname{TPU}_{1.1}(y)=\operatorname{TPU}_{2.1}(y)=\operatorname{TPU}_{3.1}(y), \\
& \operatorname{TPU}_{2}(y)=\operatorname{TPU}_{1.2}(y) \\
& \operatorname{TPU}_{3}(y)=\operatorname{TPU}_{1.3}(y)=\operatorname{TPU}_{2.3}(y)
\end{aligned}
$$
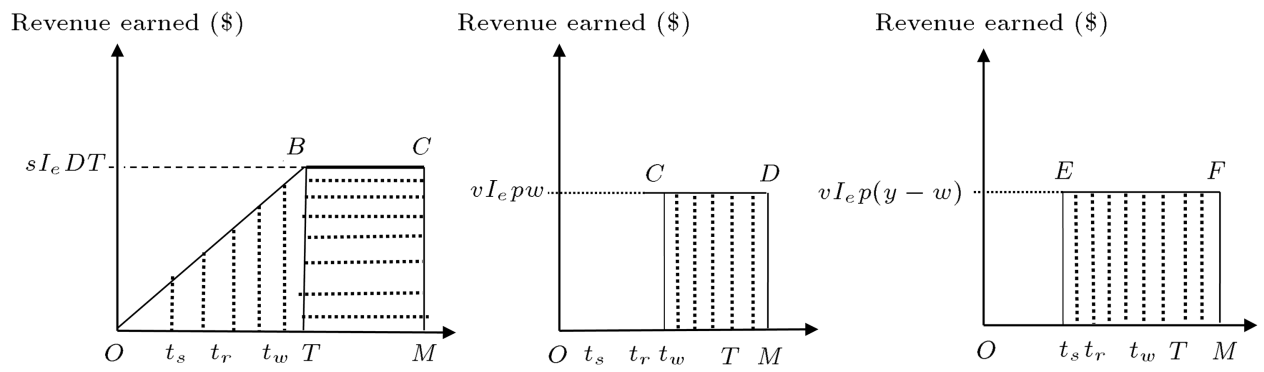

Figure 20. Graphical representation of interest earned and interest charged for $t_{s}<t_{r}<t_{w}<T<M$. 


$$
\begin{aligned}
T P_{3.5}(y)= & \left\{s D T+v y p+\frac{s I_{e} D T^{2}}{2}+s I_{e} D T(M-T)+v I_{e} p(y-w)\left(M-t_{s}\right)+v I_{e} p w\left(M-t_{w}\right)\right\} \\
& -\left\{\begin{array}{l}
k+c y+d y+h_{r}\left\{\frac{y-w}{\beta}(1-p)-\frac{D}{\beta^{2}}\left\{\ln \left(\frac{\beta}{D}(y-w)\left(1-p e^{\beta t_{s}}\right)+1\right)\right\}\right\} \\
+h_{o}\left\{\frac{w}{\alpha}(1-p)-\frac{D}{\alpha^{2}} \ln \left\{\frac{\alpha}{D}\left(w-w p e^{\alpha t_{w}}\right) e^{-\alpha t_{r}}+1\right\}\right\}
\end{array}\right\} .
\end{aligned}
$$

Box XV

$\mathrm{TPU}_{4}(y)=\operatorname{TPU}_{1.4}(y)=\mathrm{TPU}_{2.4}(y)$

$\operatorname{TPU}_{5}(y)=\mathrm{TPU}_{1.5}(y)=\mathrm{TPU}_{2.5}(y)=\mathrm{TPU}_{3.5}(y)$,

$\mathrm{TPU}_{6}(y)=\mathrm{TPU}_{2.2}(y)=\mathrm{TPU}_{3.2}(y)$,

$\mathrm{TPU}_{7}(y)=\mathrm{TPU}_{3.3}(y)$,

$\mathrm{TPU}_{8}(y)=\mathrm{TPU}_{3.4}(y)$.

The main objective is to obtain the optimal value of $y$, which maximizes the total profit function $\operatorname{TPU}_{i}(y)$. In order to determine the optimal value of $y$, which maximizes the total profit per unit time, the necessary and sufficient conditions for optimality are:

$$
\frac{d\left(\operatorname{TPU}_{i}(y)\right)}{d y}=0
$$

and:

$$
\frac{d^{2}\left(\mathrm{TPU}_{i}(y)\right)}{d y^{2}} \leq 0 .
$$

\section{Special cases}

a. When $M=0, I_{e}=0$, and $I_{p}=0$, i.e. there is no trade credit, the total profit per unit time becomes:

$T P(y)=\frac{1}{T}$

$$
\left[\begin{array}{c}
\text { sDT }+ \text { vyp } \\
k+c y+d y+h_{r}\left\{\frac{y-w}{\beta}(1-p)\right. \\
\left.-\frac{D}{\beta^{2}}\left\{\ln \left(\frac{\beta}{D}(y-w)\left(1-p e^{\beta t_{s}}\right)+1\right)\right\}\right\} \\
+h_{o}\left\{\frac{w}{\alpha}(1-p)\right. \\
\left.-\frac{D}{\alpha^{2}} \ln \left\{\frac{\alpha}{D}\left(w-w p e^{\alpha t_{w}}\right) e^{-\alpha t_{r}}+1\right\}\right\}
\end{array}\right\}
$$

which is the same profit function as that in the model of Jaggi et al. [19];

b. When $\alpha=\beta=0, M=0, I_{e}=0$, and $I_{p}=0$, i.e. there is no deterioration and no trade credit, the total profit per unit time becomes:

$$
\begin{aligned}
& \operatorname{TPU}(y)=D\left(s-v+\frac{h_{r}(y-w)^{2}}{x y}+\frac{h_{o} w^{2}}{x y}\right) \\
& +\frac{D}{(1-p)}\left(v-\frac{k}{y}-c-d-\frac{h_{r}(y-w)^{2}}{x y}-\frac{h_{o} w^{2}}{x y}\right) \\
& -\frac{h_{r}(y-w)^{2}(1-p)}{2 y}-h_{o}\left(w(1-p)-\frac{w^{2}(1-p)}{2 y}\right),
\end{aligned}
$$

which is the same profit function as that given by Chung et al. [18].

c. When $h_{r}=h_{w}, M=0, I_{e}=0$, and $I_{p}=0$, i.e. there is no trade credit and storage capacity of OW is unlimited, the total profit per unit time becomes:

$$
\begin{aligned}
\operatorname{TPU}(y) & =s D+\frac{h D}{\alpha} \\
+ & \frac{\alpha y\left(v p-c-d-\frac{h}{\alpha}(1-p)\right)-k \alpha}{\ln \left(y+\frac{D}{\alpha}-p y e^{\alpha t_{s}}\right)-\ln \left(\frac{D}{\alpha}\right)},
\end{aligned}
$$

which is the same profit function as that obtained by Moussawi-Haidar et al. [8].

d. When $h_{r}=h_{w}, \alpha=\beta=0, M=0, I_{e}=0$, and $I_{p}=0$, i.e. there is no deterioration and no trade credit, and storage capacity of OW is unlimited, the total profit per unit time becomes,

$$
\begin{aligned}
& \operatorname{TPU}(y)=D\left(s-v+\frac{h y}{x}\right) \\
& +\frac{D}{(1-p)}\left(v-\frac{k}{y}-c-d-\frac{h y}{x}\right)-\frac{h y(1-p)}{2},
\end{aligned}
$$

which is the same profit function as that obtained by Salameh and Jaber [4].

e. When $h_{r}=h_{w}, s=c, \alpha=0, \beta=0, p=0$, and storage capacity of OW is unlimited, the proposed model is same as that of Goyal [9]. 


\section{Solution procedure}

In order to find the optimal value of $y^{*}$, which maximizes the total profit function, the following algorithm is proposed:

Step 1. Determine $y^{*}=y_{1}$ from Eq. (80). Now, using the value of $y_{1}$, calculate the values of $t_{w}, t_{s}$, $t_{r}$, and $T$. If $0<M \leq t_{w}<t_{s}<t_{r}$ or $0<M \leq t_{s}<$ $t_{w}<t_{r}$ or $0<M \leq t_{s}<t_{r}<t_{w}$, then the optimal value of total profit is derived from Eq. (79a);

Step 2. Determine $y *=y_{2}$ from Eq. (80). Now, using the value of $y_{2}$, calculate the values of $t_{w}, t_{s}$, $t_{r}$, and $T$. If $t_{w}<M \leq t_{s}<t_{r}$, then the optimal value of total profit is obtained from Eq. (79b);

Step 3. Determine $y *=y_{3}$ from Eq. (80). Now, using the value of $y_{3}$, calculate the values of $t_{w}, t_{s}$, $t_{r}$, and $T$. If $t_{w}<t_{s}<M \leq t_{r}$ or $t_{s}<t_{w}<M \leq t_{r}$, then the optimal value of total profit is determined from Eq. (79c);

Step 4. Determine $y *=y_{4}$ from Eq. (80). Now, using the value of $y_{4}$, calculate the values of $t_{w}, t_{s}$, $t_{r}$, and $T$. If $t_{w}<t_{s}<t_{r}<M \leq T$ or $t_{s}<t_{w}<$ $t_{r}<M \leq T$, then the optimal value of total profit is calculated from Eq. (79d);

Step 5. Determine $y *=y_{5}$ from Eq. (80). Now, using the value of $y_{5}$, calculate the values of $t_{w}, t_{s}$, $t_{r}$, and $T$. If $t_{w}<t_{s}<t_{r}<T<M$ or $t_{s}<t_{w}<t_{r}<$ $T<M$ or $t_{s}<t_{r}<t_{w}<T<M$, then the optimal value of total profit is computed from Eq. (79e);

Step 6. Determine $y *=y_{6}$ from Eq. (80). Now, using the value of $y_{6}$, calculate the values of $t_{w}, t_{s}$, $t_{r}$, and $T$. If $t_{s}<M \leq t_{w}<t_{r}$ or $t_{s}<M \leq t_{r}<t_{w}$, then the optimal value of total profit is derived from Eq. (79f);

Step 7. Determine $y *=y_{7}$ from Eq. (80). Now, using the value of $y_{7}$, calculate the values of $t_{w}, t_{s}$, $t_{r}$, and $T$. If $t_{s}<t_{r}<M \leq t_{w}$, then the optimal value of total profit is obtained from Eq. (79g);

Step 8. Determine $y *=y_{8}$ from Eq. (80). Now, using the value of $y_{8}$, calculate the values of $t_{w}, t_{s}$, $t_{r}$, and $T$. If $t_{s}<t_{r}<t_{w}<M \leq T$, then the optimal value of total profit is calculated from Eq. (79h).

\section{Numerical examples}

This section presents three numerical examples in order to illustrate the proposed inventory model.

Example 1. The values of parameters are: $w=500$ units (thus, $t_{w}=0.008$ year), $D=15000$ units/year, $\alpha=20 \%, \beta=12.5 \%, k=\$ 1000 /$ cycle, $h_{r}=\$ 7 /$ unit /year, $h_{o}=\$ 5 /$ unit/year, $x=60000$ unit/year, $c=$ $\$ 45 /$ unit, $s=\$ 70 /$ unit, $v=\$ 30 /$ unit, $d=\$ 1.0 /$ unit,
$M=20$ days, and the percentage of defective random variable $p$ with p.d.f is:

$$
f(p)=\left\{\begin{array}{ll}
10 & 0 \leq p \leq 0.1 \\
0 & \text { otherwise }
\end{array} \quad E(p)=0.05 .\right.
$$

Two cases are considered:

(a) Let $I_{e}=0.10 /$ year and $I_{p}=0.12 /$ year $\left(s I_{e}>\right.$ $\left.c I_{p}\right)$. Results are obtained, using the proposed algorithm, as $y^{*}=1311$. Substituting the optimal value of $y^{*}$ in the expressions of $t_{s}, t_{r}, T$, and $\operatorname{TPU}^{*}(y)$, we get $t_{s}^{*}=0.0135$ year, $t_{r}^{*}=0.051$ year, $T^{*}=0.082$ year, and $\operatorname{TPU}^{*}(y)=\$ 328198$;

(b) Let $I_{e}=0.05 /$ year and $I_{p}=0.08 /$ year $\left(s I_{e}<\right.$ $\left.c I_{p}\right)$. Results are obtained, using the proposed algorithm, as $y^{*}=1408$. Substituting the optimal value of $y^{*}$ in the expressions of $t_{s}, t_{r}, T$, and $\operatorname{TPU}^{*}(y)$, we get $t_{s}^{*}=0.0151$ year, $t_{r}^{*}=0.057$ year, $T^{*}=0.088$ year, and $\operatorname{TPU}^{*}(y)=\$ 327362$.

Example 2. Here, the values of parameters are: $w$ $=800$ units (thus $t_{w}=0.013$ year), $D=15000$ units/ year, $\alpha=20 \%, \beta=12.5 \%, k=\$ 1000 /$ cycle, $h_{r}=\$ 6$ /unit/year, $h_{o}=\$ 6 /$ unit/year, $x=60000$ unit/year, $c=\$ 35 /$ unit, $s=\$ 60 /$ unit, $v=\$ 25 /$ unit, $d=\$ 1.0 /$ unit, $M=18$ days, and the percentage of defective random variable $p$ with p.d.f is:

$$
f(p)=\left\{\begin{array}{ll}
10 & 0 \leq p \leq 0.1 \\
0 & \text { otherwise }
\end{array} \quad E(p)=0.05 .\right.
$$

Now, we consider two cases:

(a) Let $I_{e}=0.08 /$ year and $I_{p}=0.10 /$ year $\left(s I_{e}>\right.$ $\left.c I_{p}\right)$. Results are obtained, using the proposed algorithm, as $y^{*}=1478$. Substituting the optimal value of $y^{*}$ in the expressions of $t_{s}, t_{r}, T$, and $\mathrm{TPU}^{*}(y)$, we get $t_{s}^{*}=0.0113$ year, $t_{r}^{*}=0.043$ year, $T^{*}=0.093$ year, and $\operatorname{TPU}^{*}(y)=\$ 331970$;

(b) Let $I_{e}=0.04 /$ year and $I_{p}=0.07 /$ year $\left(s I_{e}<\right.$ $\left.c I_{p}\right)$. Results are obtained, using the proposed algorithm, as $y^{*}=1555$. Substituting the optimal value of $y^{*}$ in the expressions of $t_{s}, t_{r}, T$, and $\mathrm{TPU}^{*}(y)$, we get $t_{s}^{*}=0.0126$ year, $t_{r}^{*}=0.048$ year, $T^{*}=0.098$ year, and $\operatorname{TPU}^{*}(y)=\$ 331655$.

Example 3. Here, the values of parameters are: $w$ $=1200$ units (thus $t_{w}=0.02$ year), $D=15000$ units /year, $\alpha=20 \%, \beta=12.5 \%, k=\$ 1000 /$ cycle, $h_{r}=$ $\$ 6 /$ unit/year, $h_{o}=\$ 6 /$ unit/year, $x=60000$ unit/year, $c=\$ 35 /$ unit, $s=\$ 60 /$ unit, $v=\$ 25 /$ unit, $d=\$ 1.0 /$ unit, $M=20$ days, and the percentage of defective random variable $p$ with p.d.f is:

$$
f(p)=\left\{\begin{array}{ll}
10 & 0 \leq p \leq 0.1 \\
0 & \text { otherwise }
\end{array} \quad E(p)=0.05 .\right.
$$


Now, we consider two cases:

(a) Let $I_{e}=0.10 /$ year and $I_{p}=0.12 /$ year $\left(s I_{e}>\right.$ $\left.c I_{p}\right)$. Results are obtained, using the proposed algorithm, as $y^{*}=1394$. Substituting the optimal value of $y^{*}$ in the expressions of $t_{s}, t_{r}, T$, and $\mathrm{TPU}^{*}(y)$, we get $t_{s}^{*}=0.0032$ year, $t_{r}^{*}=0.012$ year, $T^{*}=0.087$ year, and $\mathrm{TPU}^{*}(y)=\$ 332178 ;$

(b) Let $I_{e}=0.05 /$ year and $I_{p}=0.08 /$ year $\left(s I_{e}<\right.$ $\left.c I_{p}\right)$. Results are obtained, using the proposed algorithm, as $y^{*}=1492$. Substituting the optimal value of $y^{*}$ in the expressions of $t_{s}, t_{r}, T$, and $\operatorname{TPU}^{*}(y)$, we get $t_{s}^{*}=0.0049$ year, $t_{r}^{*}=0.018$ year, $T^{*}=0.094$ year, and $\operatorname{TPU}^{*}(y)=\$ 331542$.

\section{Sensitivity analysis}

Sensitivity analysis was performed to study the effects of permissible delay $(M)$, interest earned $\left(I_{e}\right)$, interest paid $\left(I_{p}\right)$, deterioration ( $\alpha$ and $\beta$ ), percentage of defective items $(p)$, and change in the capacity of OW $(w)$ on the optimal lot size $\left(y^{*}\right)$ and the total profit per unit time $\operatorname{TPU}^{*}(y)$. The observations are shown in Tables 2 to 5 .

From Table 2, it is observed that when $s I_{e}>c I_{p}$, cycle lengths of RW and OW as well as the optimal order quantity decrease as the permissible delay period increases along with the increase in annual profit. This insinuates that trade credit turns beneficial for

Table 2. Effect of change in capacity of owned warehouse and trade credit period on the model $\left(s I_{e}>c I_{p}\right)$.

\begin{tabular}{cccccccc}
\hline $\boldsymbol{W}$ & $\boldsymbol{M}$ (days) & $\boldsymbol{t}_{\boldsymbol{s}}$ & $\boldsymbol{t}_{\boldsymbol{r}}$ & $\boldsymbol{T}$ & $\boldsymbol{y}^{*}$ & TPU* $\left.^{*} \boldsymbol{y}\right)$ & Case \\
\hline \multirow{2}{*}{400} & 10 & 0.0166 & 0.063 & 0.088 & 1394 & 325628 & $t_{w}<t_{s}<M<t_{r}<T$ \\
$\left(t_{w}=0.007\right)$ & 20 & 0.0152 & 0.058 & 0.082 & 1312 & 328272 & $t_{w}<t_{s}<M<t_{r}<T$ \\
& 30 & 0.0147 & 0.056 & 0.081 & 1283 & 331110 & $t_{w}<t_{s}<t_{r}<T<M$ \\
& 10 & 0.0070 & 0.027 & 0.083 & 1322 & 325280 & $t_{s}<t_{w}<M<t_{r}<T$ \\
900 & 20 & 0.0068 & 0.026 & 0.082 & 1305 & 327897 & $t_{s}<t_{w}<t_{r}<M<T$ \\
$\left(t_{w}=0.015\right)$ & 30 & 0.0063 & 0.024 & 0.080 & 1276 & 330737 & $t_{s}<t_{w}<t_{r}<T<M$ \\
& 10 & 0.0019 & 0.007 & 0.083 & 1315 & 325107 & $t_{s}<t_{r}<t_{w}<M<T$ \\
1200 & 20 & 0.0016 & 0.006 & 0.081 & 1298 & 327725 & $t_{s}<t_{r}<t_{w}<M<T$ \\
$\left(t_{w}=0.020\right)$ & 30 & 0.0012 & 0.004 & 0.080 & 1270 & 330569 & $t_{s}<t_{r}<t_{w}<T<M$ \\
\hline
\end{tabular}

Table 3. Effect of change in capacity of owned warehouse and trade credit period on the model $\left(s I_{e}<c I_{p}\right)$.

\begin{tabular}{cccccccc}
\hline $\boldsymbol{W}$ & $\boldsymbol{M}$ (days) & $\boldsymbol{t}_{\boldsymbol{s}}$ & $\boldsymbol{t}_{\boldsymbol{r}}$ & $\boldsymbol{T}$ & $\boldsymbol{y}^{*}$ & $\boldsymbol{T P U}^{*}(\boldsymbol{y})$ & Case \\
\hline \multirow{2}{*}{400} & 10 & 0.0168 & 0.063 & 0.088 & 1406 & 325950 & $t_{w}<t_{s}<M<t_{r}<T$ \\
$\left(t_{w}=0.007\right)$ & 20 & 0.0168 & 0.064 & 0.089 & 1409 & 327450 & $t_{w}<t_{s}<t_{r}<M<T$ \\
& 30 & 0.0169 & 0.064 & 0.089 & 1412 & 328931 & $t_{w}<t_{s}<t_{r}<T<M$ \\
& 10 & 0.0083 & 0.031 & 0.088 & 1398 & 325565 & $t_{s}<t_{w}<M<t_{r}<T$ \\
900 & 20 & 0.0083 & 0.032 & 0.088 & 1400 & 327062 & $t_{s}<t_{w}<t_{r}<M<T$ \\
$\left(t_{w}=0.015\right)$ & 30 & 0.0084 & 0.032 & 0.088 & 1403 & 328544 & $t_{s}<t_{w}<t_{r}<T<M$ \\
& 10 & 0.0032 & 0.012 & 0.087 & 1390 & 325391 & $t_{s}<t_{r}<t_{w}<M<T$ \\
& 20 & 0.0032 & 0.012 & 0.087 & 1391 & 326887 & $t_{s}<t_{r}<t_{w}<M<T$ \\
$\left(t_{w}=0.02\right)$ & 30 & 0.0032 & 0.012 & 0.088 & 1394 & 328368 & $t_{s}<t_{r}<t_{w}<T<M$ \\
\hline
\end{tabular}

Table 4. Effect of change of $I_{e}$ and $I_{p}$ on optimal replenishment policy ( $M=10$ days).

\begin{tabular}{|c|c|c|c|c|c|c|}
\hline \multirow{3}{*}{$I_{p}$} & \multicolumn{6}{|c|}{$I_{e}$} \\
\hline & \multicolumn{2}{|r|}{0.03} & \multicolumn{2}{|r|}{0.05} & \multicolumn{2}{|r|}{0.07} \\
\hline & $y^{*}$ & $\operatorname{TPU}^{*}(y)$ & $y^{*}$ & $\operatorname{TPU}^{*}(y)$ & $y^{*}$ & $\mathrm{TPU}^{*}(\boldsymbol{y})$ \\
\hline 0.1 & 928 & 338260 & 920 & 338382 & 898 & 338454 \\
\hline 0.15 & 888 & 338056 & 880 & 338184 & 872 & 338312 \\
\hline 0.2 & 854 & 337876 & 847 & 338008 & 840 & 338141 \\
\hline
\end{tabular}


Table 5. Effect of change of percentage of defective items on the model $\left(w=900, \alpha=0.2, \beta=0.125, I_{e}=0.1 /\right.$ year, $I_{p}=0.12 /$ year $)$.

\begin{tabular}{ccccccc}
\hline $\begin{array}{c}\text { Percentage } \\
\text { of defective } \\
\text { items } \boldsymbol{p}\end{array}$ & $\boldsymbol{t}_{\boldsymbol{s}}$ & $\boldsymbol{t}_{\boldsymbol{w}}$ & $\boldsymbol{t}_{\boldsymbol{r}}$ & $\boldsymbol{T}$ & $\boldsymbol{y}$ & TPU $^{*}(\boldsymbol{y})$ \\
\hline 0.025 & 0.0128 & 0.015 & 0.030 & 0.065 & 1666 & 562408 \\
0.05 & 0.0133 & 0.015 & 0.030 & 0.064 & 1700 & 551454 \\
0.075 & 0.0139 & 0.015 & 0.031 & 0.064 & 1734 & 539900 \\
\hline
\end{tabular}

economic ordering policy. Thus, the retailer should procure less quantity and take the advantage of permissible delay in payments more often.

Now, from Table 3 , it is observed that if $s I_{e}<c I_{p}$, then, as the permissible delay period increases, the optimal order quantity and, thus, the total annual profit increase. This implies that the retailer should procure more quantity to avoid higher interest charges on the inventory left after the credit period, which eventually results in higher profits.

Table 4 shows that as interest earned $\left(I_{e}\right)$ by retailer increases, the optimal order quantity $\left(y^{*}\right)$ decreases; but, expected profit increases, implying that when the interest earned per dollar is high, the expected total cost is low, which results in higher expected profit. Also, increase in interest paid $\left(I_{p}\right)$ by retailer results in decrease in optimal order quantity, as well as the expected profit, because the expected total cost increases when the interest payable rate for the items stocked is high. Thus, a retailer should order less but more frequently when the interest payable rate per dollar is high.

Table 5 clearly shows that as the percentage of imperfect quality items $(p)$ increases, the optimal order quantity $\left(y^{*}\right)$ increases to meet the demand out of perfect quality items; but, the retailer's total profit $\operatorname{TPU}^{*}(y)$ decreases significantly. Thus, the retailer should be more vigilant when ordering and should carefully select the suppliers.

\section{Conclusion}

This paper amalgamates the concepts of two warehouses and the effect of deterioration on the retailer's lot when the items are of imperfect quality under the permissible delay of payments. The screening rate is assumed to be more than the demand rate so that the demand can be fulfilled out of the products that are found to be of perfect quality while the screening is in process. The numerical examples followed by the sensitivity analysis of various model parameters indicate that in case of highly deteriorating products, order should be made more frequently to reduce the losses due to deterioration. Also, as the defective items increase, the total profit decreases; in such a situation, the corrective measures need to be taken in order to procure good quality products. The results of sensitivity analysis also show that the presence of trade credit period is beneficent for retailer ordering policy. The retailer should order more to avoid higher interest charged after the grace period that eventually increases his/her total profit under the situation $s I_{e}<c I_{p}$; whereas, in other situation, i.e. $s I_{e}>c I_{p}$, the retailer should order less to avail the benefit of permissible delay more frequently. Also, as the rate of interest to be paid increases, the retailer should order less but more frequently. The proposed inventory model is a general framework as it includes numerous previous models.

\section{References}

1. Porteus, E.L. "Optimal lot sizing, process quality improvement and setup cost reduction", Oper. Res., 34(1), pp. 137-144 (1986).

2. Rosenblatt, M. and Lee, H. "Economic production cycles with imperfect production processes", IIE. Trans., 18(1), pp. 48-55 (1986).

3. Lee, H.L. and Rosenblatt, M.J. "Simultaneous determination of production cycles and inspection schedules in a production system", Manage. Sci., 33(9), pp. 1125-1137 (1987).

4. Salameh, M.K. and Jaber, M.Y. "Economic production quantity model for items with imperfect quality", Int. J. Prod. Econ., 64(3), pp. 59-64 (2000).

5. Cárdenas-Barrón, L.E. "Observation on: Economic production quantity model for items with imperfect quality", Int. J. Prod. Econ., 64, pp. 59-64 (2000), Int. J. Prod. Econ., 67(2), p. 201 (2000).

6. Goyal, S.K. and Cárdenas-Barrón, L.E. "Note on: Economic production quantity model for items with imperfect quality-a practical approach", Int. J. Prod. Econ., 77(1), pp. 85-87 (2002).

7. Papachristos, S. and Konstantaras, I. "Economic ordering quantity models for items with imperfect quality", Int. J. Prod. Econ., 100(1), pp. 148-154 (2006).

8. Moussawi-Haidar, L., Salameh, M. and Nasr, W. "Effect of deterioration on the instantaneous replenishment model with imperfect quality items", Appl. Math. Model., 38(24), pp. 5956-5966 (2014).

9. Goyal, S.K. and Giri, B.C. "Recent trends in modeling of deteriorating inventory", Eur. J. Oper. Res., 134(1), pp. 1-16 (2001). 
10. Bakker, M., Riezebos, J. and Teunter, R.H. "Review of inventory systems with deterioration since 2001", Eur. J. Oper. Res., 221(2), pp. 275-284 (2012).

11. Hartley, V.R., Operations Research - A Managerial Emphasis, Good Year Publishing Company, California, pp. 315-317 (1976).

12. Das, B., Maity, K. and Maiti, M. "A two warehouse supply-chain model under possibility/necessity/credibility measures", Math. Comput. Model., 46(3), pp. 398-409 (2007).

13. Hsieh, T.P., Dye, C.Y. and Ouyang, L.Y. "Determining optimal lot size for a two-warehouse system with deterioration and shortages using net present value", Eur. J. Oper. Res., 191(1), pp. 182-192 (2008).

14. Lee, C.C. "Two-warehouse inventory model with deterioration under FIFO dispatching policy", Eur. J. Oper. Res., 174(2), pp. 861-873 (2006).

15. Bhunia, A.K. and Maiti, M. "A two warehouses inventory model for deteriorating items with a linear trend in demand and shortages", J. Oper. Res. Soc., 49, pp. 287-292 (1998).

16. Niu, B. and Xie, J. "A note on two-warehouse inventory model with deterioration under FIFO dispatch policy", Eur. J. Oper. Res., 190(2), pp. 571-577 (2008).

17. Bhunia, A.K., Jaggi, C.K., Sharma, A. and Sharma, R. "A two-warehouse inventory model for deteriorating items under permissible delay in payment with partial backlogging", Appl. Math. Comput., 232, pp. 11251137 (2014).

18. Chung, K.J., Her, C.C. and Lin, S.D. "A twowarehouse inventory model with imperfect quality production process", Comput. Ind. Eng., 56(1), pp. 193-197 (2009).

19. Jaggi, C.K., Tiwari, S. and Shafi, A. "Effect of deterioration on two-warehouse inventory model with imperfect quality", Comput. Ind. Eng., 88, pp. 378-385 (2015).

\section{Biographies}

Chandra Kant Jaggi is Professor and Head of the Department of Operational Research at University of Delhi, India. He has been Fellow Member of International Science Congress Association since 2012. He was awarded the Certificate of Excellence in 2nd Academic Brilliance Award 2014 by EET CRS, Research wing for excellence in Professional Education \& Industry, Noida. In 2010, he was awarded Certificate for his Exceptional Contributions in the field of Inventory Management by Lingaya's University, Faridabad, and in 2009, was awarded Certificate for his Significant Contributions in Operation Management by the Society of Reliability Engineering, Quality and Operations Management, New Delhi. Also, he is a recipient of Shiksha Rattan Puraskar (for Meritorious Services, Outstanding
Performance and Remarkable Role) in 2007 by India International Friendship Society. He is Life Member of Operational Research Society of India, Indian Science Congress Association, and Fellow Member of International Science Congress Association, Computer Society of India, The Society of Mathematical Sciences, University of Delhi, India, Society for Reliability Engineering, Quality and Operations Management, Indian Society for Probability and Statistics. His research interest lies in the field of supply chain and inventory management. He has guided $12 \mathrm{PhD}$ and $21 \mathrm{MPhil}$ candidates in Operations Research. He has published 7 book chapters and also papers in several national and international journals. He is also a reviewer of many international/national journals. He is Ex-Editor-inChief of International Journal of Inventory Control and Management; Associate Editor of International Journal of System Assurance Engineering and Management, Springer; Co-Editor/Reviewer-In-Charge of The Gstf Journal of Mathematics, Statistics and Operations Research; and a member of the Editorial Board of the IJSS: Operations \& Logistics, International Journal of Services Operations and Informatics, American Journal of Operational Research, International Journal of Enterprise Computing and Business Systems, Journal of Applied Sciences Research, and Australian Journal of Basic and Applied Sciences. He has traveled to Canada, Philippines, Macau, Iran, and different parts of India to deliver keynote addresses and invited talks.

Leopoldo Eduardo Cárdenas-Barrón is currently a Professor in the School of Engineering and Sciences at Tecnologico de Monterrey, Campus Monterrey, México. $\mathrm{He}$ is also a faculty member in the Department of Industrial and Systems Engineering at Tecnologico de Monterrey. He was the Associate Director of the Industrial and Systems Engineering programme from 1999 to 2005. Moreover, he was the Associate Director of the Department of Industrial and Systems Engineering from 2005 to 2009. His research areas are primarily related to inventory planning and control, logistics, and supply chain. He has published papers and technical notes in many international journals. He has co-authored one book in the field of simulation in Spanish. He is also editorial board member in several international journals.

Sunil Tiwari is an Assistant Professor in Department of Mathematics, Ambedkar University, Delhi. He received his $\mathrm{PhD}$ degree (Inventory Management) in 2016, M. Phil. (Inventory Management) in 2013 and MSc degree (Operational Research) in 2011 from Department of Operational Research, Faculty of Mathematical Sciences, University of Delhi. His research areas include primarily related to inventory planning and control, logistics, and supply chain. He has 
published research papers in International Journal of Production Economics, Computers and Industrial Engineering, Annals of Operations Research, Applied Mathematics \& Information Sciences, International Journal of Industrial Engineering Computations, International Journal of Operational Research, Iranian Journal of Fuzzy Systems, and one book chapter in this area.
Ali Akbar Shafi is an associate application developer at Oracle Financial Software Services. He completed his BSc degree in Electrical and Electronics Engineering at Birla Institute of Technology, Mesra, in 2014. He is primarily interested in research on optimization, logistics, and supply chain management. He has published a paper in Computers and Industrial Engineering. 